\title{
Extreme returns in the European financial crisis
}

Article

Accepted Version

Chouliaras, A. and Grammatikos, T. (2017) Extreme returns in the European financial crisis. European Financial Management, 23 (4). pp. 728-760. ISSN 1468-036X doi: https://doi.org/10.1111/eufm.12112 Available at https://centaur.reading.ac.uk/69813/

It is advisable to refer to the publisher's version if you intend to cite from the work. See Guidance on citing.

To link to this article DOI: http://dx.doi.org/10.1111/eufm.12112

Publisher: Wiley

All outputs in CentAUR are protected by Intellectual Property Rights law, including copyright law. Copyright and IPR is retained by the creators or other copyright holders. Terms and conditions for use of this material are defined in the End User Agreement.

\section{www.reading.ac.uk/centaur}

\section{CentAUR}

Central Archive at the University of Reading

Reading's research outputs online 


\title{
Extreme Returns in the European Financial Crisis
}

\author{
Andreas Chouliaras*, Theoharry Grammatikos**
}

\begin{abstract}
We examine the transmission of financial shocks among three groups of countries: the Europeriphery countries (Portugal, Ireland, Italy, Greece, Spain), the Euro-core countries (Germany, France, the Netherlands, Finland, Belgium), and the major European Union -but not euro- countries (Sweden, UK, Poland, Czech Republic, Denmark). Using extreme returns on daily stock market data from January 2004 until March 2013, we find that transmission effects are present for the tails of the returns distributions for the Pre-crisis, the US-crisis and the Euro-crisis periods from the Euro-periphery group to the Non-euro and the Euro-core groups. Within group effects are stronger in the crisis periods. Even before the two crises there was a significant shock transmission channel from the Euro-periphery to the Euro-core and the Non-euro. During the crises the shocks transmitted were more substantial (in some cases, extreme bottom returns doubled). As extreme returns have become much more severe during the financial crisis periods, the expected losses on extreme return days have increased significantly. Given the fact that stock market capitalizations in these country groups are in trillions of Euros, a $1 \%$ or $2 \%$ increase in extreme bottom returns (in crisis periods) can lead to aggregate losses of tens of billions Euros in one single trading day.
\end{abstract}

JEL classification: G01, G15.

Keywords: Financial Crisis, Financial Contagion, Spillover, Euro-crisis, Stock Markets.

* Corresponding author. E-mail address: a.chouliaras@icmacentre.ac.uk

** Andreas Chouliaras is with the ICMA Centre, Henley Business School, University of Reading. Theoharry Grammatikos is with the Luxembourg School of Finance, University of Luxembourg. We are especially grateful to John Doukas (the editor) and three anonymous referees for very helpful suggestions. We thank Gerard Hoberg, Tim Loughran, Bill McDonald, Thorsten Lehnert, Dimitrios Gounopoulos, Konstantinos Tsiveriotis, Christoph Schommer, Chris Brooks, Adrian Bell, George Alexandridis, Apostolos Christopoulos, Roman Kraussl, Aigli Siouti, Alexandros Chouliaras and Sara Goumalatsou, as well as seminar participants at the Luxembourg School of Finance and the ICMA Centre, Henley Business School, University of Reading for helpful comments. Any remaining errors are the authors' alone. 


\section{Introduction}

The recent global financial crisis began as a crisis in the subprime mortgage loan business in the United States of America in 2007 and continued with multiple waves of financial distress that hit the global financial markets. Since the beginning of 2010 the Euro area faces a severe financial crisis (Doukas (2012)). What started off as a sovereign debt crisis in Greece soon transmitted itself to Portugal, Ireland, Cyprus and, at least partially, to Spain and Italy. Pretty soon it became clear for Europe that beneath the sovereign debt crisis surface there also existed a severe banking crisis (Caselli, Gandolfi, and Soana (2014)). The propagation of financial distress from one country to another, with stock markets, bond yields and CDS spreads being affected, makes the case of studying the transmission of extreme returns more pertinent than ever ${ }^{1}$.

A number of researchers investigate the recent eurozone financial crisis and its transmission effects, giving particular emphasis on the sovereign debt and the Credit Default Swaps (CDS) markets. Missio and Watzka (2011) report the existence of contagion effects using dynamic conditional correlation models. Metiu (2012) employs a simultaneous equations model and examines the tails of bond yield distributions, an approach derived from the Extreme Value Theory and Value-at-Risk, and finds structural shift contagion effects for the crisis periods. Other papers, however, do not find contagion effects for the sovereign bond and the credit default swaps markets. See, for example, Caporin, Pelizzon, Ravazzolo, and Rigobon (2013) and Bhanot, Burns, Hunter, and Williams (2012).

The study of stock markets during financial crises has not been examined sufficiently in the previous literature despite them being the most liquid markets. In this paper we investigate the stock market financial transmission effects of the European financial crisis (and the US-crisis) for three groups of countries: two groups of eurozone countries, the Euro-core eurozone countries (Germany, France, Netherlands, Belgium, Finland) and the Euro-periphery eurozone countries (Portugal, Ireland, Italy, Greece, Spain), and finally a group for European Union (EU) but non euro countries (Sweden, UK, Poland, Czech Republic, Denmark). The creation of these three groups is justified mainly by the existence of the European Union and the Eurozone. The European Union is primarily a free-trade union, in which free movement of capital, labor and tradable goods take place. This has resulted in strong ties which go well beyond these trade relationships, taking also the form of a primary political union (with the existence of European Union legislation which applies to all member countries, the European Parliament, and various political and administrative authorities such as the European

\footnotetext{
${ }^{1}$ The shock transmission literature is extensive. See, for example Allen and Gale (2000), Rigobon (2002), Kaminsky, Reinhart, and Vegh (2003), Pericoli and Sbracia (2003), Bekaert, Harvey, and Ng (2005), Forbes and Rigobon (2001), Aït-Sahalia, Cacho-Diaz, and Laeven (2010), Dungey, Fry, González-Hermosillo, and Martin (2005), Corsetti, Pericoli, and Sbracia (2005), Haß, Koziol, and Schweizer (2014).
} 
Commission). The Non-euro group is heterogeneous, but their participation in the European Union justifies grouping these countries together. A subset of the European Union countries have formed the Eurozone which as well as being a free trade area, is a monetary union as well, sharing the Euro as a common currency. The heads of state of the member countries of the Eurozone meet regularly in order to coordinate policy and take decisions. The agreed measures affect all Eurozone countries. This justifies the inclusion of the Euro-core in our sample, which are the five countries with the highest market capitalizations among all Eurozone countries. Finally, the five countries that were most badly hit by the recent crisis, are Portugal, Ireland, Italy, Greece and Spain (Doukas (2013)). These five countries are part of the European Union and the Eurozone, which is why we group them together in the Euro-periphery group. The transmission of shocks between the Euro-core and the Euro-periphery is interesting, because, being part of the same trading union and the same monetary union, financial problems in one group may indeed also affect the other groups. The Euro-core countries were called upon to provide financial aid (along with the other Eurozone countries, the European Central Bank and the International Monetary Fund) to the Euro-periphery countries that were in need. Since hundreds of billions Euros were provided in assistance, it is worth examining the effect of extreme stock market shocks to the three country groups for one more reason: the provision of financial assistance may not only have been an act of solidarity, but also an act of self interest for the Euro-core and the Non-euro group, if this financial assistance was able to mitigate the transmitted shocks 2 ,

The correlations framework has been widely used by previous authors in related studies but there is no consensus in the literature as to how to best define contagion when using that framework. Forbes and Rigobon (2001) claim that heteroskedasticity biases correlation tests for contagion? ${ }^{3}$, To avoid this problem we follow the extreme returns approach proposed mainly in two papers, Bae, Karolyi, and Stulz (2003) and Boyson, Stahel, and Stulz (2010). Bae et al. (2003) examine the coincidence of extreme return shocks across countries within a group and across groups, while Boyson et al. (2010) study hedge funds contagion. A number of other studies have also used this methodology 4 . In a related paper, Christiansen (2014) uses a sample of $14 \mathrm{EU}$ countries, and proposes two classification approaches for extreme returns: one which calculates extreme returns separately for every country, and one which pools stock returns ("multivariate classification scheme"), and calculates extreme returns

\footnotetext{
${ }^{2}$ Although the Non-euro countries did not directly contribute to the financial assistance packages, they are indirectly affected through the IMF contributions. On top of that, decisions to create the European Financial Stability Facility (EFSF) and the European Stability Mechanism (ESM) in order to deal with the Euro-crisis were taken by all European Union member states.

${ }^{3}$ By applying a correction they find no contagion for the 1997 Asian crisis. On the other hand, Corsetti et al. (2005) claim that the variance restrictions imposed by Forbes and Rigobon (2001) are "arbitrary and unrealistic". They find evidence for at least five countries facing contagion effects during the Hong Kong stock market crisis of 1997.

${ }^{4}$ See, for example, Markwat, Kole, and van Dijk (2009), Lucey and Sevic (2010), Christiansen and Ranaldo (2009), Gropp, Duca, and Vesala (2009), Chouliaras and Grammatikos (2015)
} 
on the overall sample. As far as extreme stock returns are concerned, Christiansen (2014) finds that it cannot be rejected that the two approaches are identical for the financial crisis period (2008 until 2012).

What is the incremental contribution of the paper to the literature? First of all, we study for effects that exist in the equity markets during the European Financial Crisis, which were (quite surprisingly) not sufficiently examined in the previous literature, who typically studied for "contagion" effects on the sovereign bonds and the credit default swaps (CDS) markets (Metiu (2012), Missio and Watzka (2011), Fabozzi, Giacometti, and Tsuchida (2016), Gündüz and Kaya (2014), Banerjee, Hung, and Lo (2015), Abad, Chuliá, and Gómez-Puig (2014)). The study of equity markets is significant, as they are the most liquid markets, and they have the highest trading volume as well. Another reason to study the effects on stock markets, is due to the fact that during the European Financial Crisis, three of the five countries that were the most badly hit (the Euro-periphery countries) were in bailout programs: Greece, Ireland and Portugal. During this period, the countries' sovereign bonds and CDS were at untradeable levels most of the time (due to extremely high spreads, there was virtually no trading taking place). An analysis that is based on assets that are not traded much during a period, is unlikely to yield very significant conclusions. One of the few papers that examines the presence of contagion effects on stock markets is Mollah, Quoreshi, and Zafirov (2016), but the setting of this paper is significantly different: the authors examine a series of bivariate regressions, calculating the correlations between day $\mathrm{t}$ and day $\mathrm{t}-1$. In our setting, we examine the effects of extreme returns dynamics from one group to another, which answers the question whether a group of countries is able to affect other groups of countries. Furthermore, the authors at Mollah et al. (2016) compare correlations without taking into account any fundamental variables, which is another disadvantage compared to our approach. A related paper to ours is Christiansen (2014) in the sense that we also find strong effects as far as the dynamics of extreme returns are concerned. A difference is that this paper separately (and econometrically) examines the three groups, taking into account the effect that goes over and beyond the effect of fundamental variables. Another paper that studies the effect of the European Financial Crisis on stock returns is Chan-Lau, Liu, and Schmittmann (2015), but this paper only takes into account the stocks of 68 banks. Indeed the study of bank stocks is significant during a financial crisis period, but this paper goes a step beyond and studies the behavior of 15 stock indices. The stock indices consist of hundreds of stocks with aggregate market capitalisations of tens of trillions euros. This way one is able to better assess the overall cost of the financial crisis on stock prices, instead of simply observing the behavior of the banking sector stocks.

Moving in line with multinomial logistic analysis, as proposed by Bae et al. (2003) and Boyson 
et al. (2010), we use control variables (covariates) in order to justify the characteristics of extreme returns. Furthermore, this approach allows us to study the effects within groups, and the crisis transmission across groups. Since it is well accepted that the most vulnerable eurozone countries -the Euro-periphery group- were the most badly hit by the Euro-crisis, our main interest is to study the crisis transmission from the Euro-periphery group to the other two groups (Euro-periphery vs. Eurocore, Euro-periphery vs. Non-euro) ${ }^{5}{ }^{6}$. We find that extreme returns in Euro-periphery countries are related to extreme returns in the Euro-core and the Non-euro country groups. In order to test if the crises result in a fundamental shift in the transmission mechanism the extreme returns methodology is applied not only on the entire period (as in previous studies), but also separately on each of the three subperiods (Pre-crisis, US-crisis, Euro-crisis).

We find that even before the two crises there was a significant shock transmission channel from the Euro-periphery to the Euro-core and the Non-euro groups. During the crises the shocks transmitted were more substantial, not only for the Euro-periphery countries, but also for the Euro-core group and the Non-euro group. Given the extremely big size of the European equity markets, a $1 \%$ or $2 \%$ increase in the magnitude of extreme bottom returns can lead to aggregate losses of tens of billions Euros in one single trading day, resulting in very important implications for investors and policy makers. The differences in the models of the three periods are further verified by using likelihood ratio tests.

The remainder of this paper is organized as follows. Section 2 presents the data. Section 3 presents the basic model and we explain how we study the crisis transmission within and across groups. Section 4 provides a set of robustness and alternative specifications. Section 5 is a conclusion.

\section{The Data}

The main area of study for this paper is the European Union. Thus, we create three country groups: the Euro-periphery group contains the periphery eurozone countries (Portugal, Ireland, Italy, Greece, Spain), the Euro-core group contains the core countries of the Eurozone (Germany, France, the Netherlands, Finland, Belgium), and the Non-euro group contains the major European Union (but not Euro) countries (Poland, Sweden, Czech Republic, UK, Denmark)7. We examine the period

\footnotetext{
${ }^{5}$ Another study that uses this approach is Thomadakis (2012), but our main difference is that he considers the Eurozone countries as one group, thus not studying the within eurozone dynamics of the various subgroups, and he studies the interactions mainly with the USA, for the industrials sectors of the stock exchanges.

${ }^{6}$ One critique on Bae et al. (2003) and Boyson et al. (2010) is that they arbitrarily pick the top and the bottom 5\% from the sample of returns to examine the joint occurrence of extreme returns. This critique has indeed some merit but a choice of cutoff points is a necessary decision in order to proceed with this methodology and to study the tails of the marginal return distributions in order to see what happens in the presence of extreme returns. The results of our study were found to be robust in the change of the percentiles.

${ }^{7}$ We take the biggest five stock markets from each group using the market capitalization ranking (as of 2011) from http://www.indexmundi.com/facts/indicators/CM.MKT.LCAP.CD/rankings
} 
from 01/01/2004 until 13/03/2013 using daily financial data obtained from the Thomson Reuters Datastream. Our selection of countries for the Eurozone follows to a large extent the studies of Missio and Watzka (2011), Caporin et al. (2013), Bhanot et al. (2012), and Metiu (2012). Country group log returns (expressed in local currency) and standard deviations are calculated on the equally weighted portfolio of the country stock market daily returns (expressed in local currency) for each group. Table 1 shows the summary statistics and correlation matrices of the percentage returns of the major stock market indices (Panel A and Panel B) ${ }^{8}$. To be able to make comparisons between normal and abnormal times in the financial markets, we split our sample into three subperiods (Pre-crisis, US-crisis Euro-crisis):

- the Pre-crisis period (from 1 January 2004 until 26 February 2007)

- the US-crisis period (from 27 February 2007 until 7 December 2009) 99

- the Euro-crisis period (from 8 December 200910 until the end of our sample period, 13 March 2013.

Insert Table 1 here

For the Pre-crisis period all groups of countries had positive mean returns, consistent with the overall optimism in the financial markets. The best performing markets were firstly the Non-euro countries $(+0.101 \%)$ followed by the Euro-periphery countries $(+0.089 \%)$. These numbers may appear to be high (a mean of $+0.101 \%$ per day leads to almost $25 \%$ per year), but one has to take into account the rally that was observed in the stock markets during the Pre-crisis period. For example, the London Stock Exchange index had a value of 273 in January 2004, and it climbed up to 1197 in February 2007, which means that in the end of the Pre-crisis period its price was almost four times higher than the beginning of the Pre-crisis period. Regarding the standard deviation we see that we have rather low values for all country groups as this was a period of relative calm for the financial markets. During the US-crisis period all country groups had a negative mean return. The Euro-periphery countries were the most badly hit with a mean (daily) return of $-0.074 \%$, followed by the Euro-core countries which had a mean (daily) return of $-0.049 \%$, then the Non-euro with a $-0.024 \%$. Compared to the Pre-crisis

\footnotetext{
${ }^{8}$ All stock indices used are the Thomson Reuters Datastream indices created for each country

${ }^{9}$ We use 27 February 2007 as the start of the financial crisis, as used by the Federal Reserve Bank of St. Louis in their Timeline of Events and Policy Actions. The timeline can be found at http://timeline.stlouisfed.org/index. cfm?p=timeline. On 27 February 2007, the Federal Home Loan Mortgage Corporation (Freddie Mac) announced that it will no longer buy the most risky subprime mortgages and mortgage-related securities.

${ }^{10}$ On 8 December 2009, the Greek sovereign debt was downgraded by Fitch from A- to BBB+ ("junk status"), with a negative outlook. The use of 8 December 2009 as the start of the Euro-crisis is well justified, as verified in other studies, such as Featherstone (2011).
} 
period, the standard deviations have increased significantly in the crisis periods for all three country groups. The descriptive statistics for the Euro-crisis period show that once more the Euro-periphery countries were the most severely affected from the financial crisis (mean daily return of $-0.016 \%$ ). The other two groups have positive mean returns for this period, indicating that they were able to better cope with the crisis. The standard deviations were lower than in the US-crisis period but still higher than the Pre-crisis period, especially for the Euro-periphery group. As far as the correlations are concerned the main remark is that they increased between the Pre-crisis and the crisis periods. The correlation between the Non-euro and the Euro-periphery group grew from the Pre-crisis value of 0.791 to 0.919 in the US-crisis period, then went down to 0.836 at the Euro-crisis period. The correlation between the Euro-periphery and the Euro-core followed a similar pattern, increasing from 0.870 Pre-crisis to 0.928 in the US-crisis, then declined to 0.876 in the Euro-crisis period, which is still much higher than the Pre-crisis period. The correlation between the Non-euro and the Euro-core group increased from 0.806 Pre-crisis to 0.912 in the US-crisis period, remaining at the elevated level of 0.926 in the Euro-crisis. To summarize, for both crisis periods (US and Euro-crisis) the correlations are higher than what they were in the Pre-crisis period, and the most hit group is found to be the Euro-periphery group, which has negative mean returns in both crisis periods.

\section{Extreme Returns}

\subsection{The Base Model}

According to Bae et al. (2003) and Boyson et al. (2010), an extreme return is one that lies below (or above) the lowest (or the highest) quantile of the marginal return distribution. This methodology concerns the counts (i.e. isntances) of joint occurrences of extreme returns within a group on a particular day. The original approach studies the number of extreme returns for the entire test period, taking as thresholds for extreme returns the 5 th and the 95 th percentiles. In our case, and in order to have a sufficient number of observations, we choose as thresholds the 10th and the 90th percentiles, as in Boyson et al. (2010) (our findings are robust to the 5th and 95th percentiles). Thus, for each country we consider returns below the 10th percentile as extreme bottom returns and those above the 90th percentile as extreme top returns for this country.

This procedure is followed for all countries in all groups. Top extreme returns are treated separately from bottom extreme returns. To demonstrate the application of the Bae et al. (2003) model, extreme bottom and top counts are reported in Table 2, using the one cutoff for the overall sample. For each country we calculate the days for which it had an extreme (bottom or top) return separately. Then, 
the extreme returns count for each group and day is given as the sum of the extreme returns for all countries that belong to that group for that specific day.

Insert Table 2 here

The left side of Table 2 presents bottom return counts and the right side shows top return counts. A count of $\mathrm{i}$ units for bottom returns is the joint occurrence of $\mathrm{i}$ extreme bottom returns on a particular day for a specific group. By counting the total number of days with extreme returns of a given number and identifying which countries participate in those events and how often we have a good overview of the extreme returns for each country and group of countries.

We notice that out of the $10 \%$ lowest returns for all Euro-periphery countries the Greek stock market had the most days (106) on which it was the only country experiencing a bottom extreme return, followed by Ireland (56 days) and Portugal (37 days). A total of 54 days are reported for the Euro-periphery countries on which all of them experienced extreme bottom returns. For the Euro-core countries, 109 days are identified in which all five countries experienced an extreme bottom return shock. On 55 days all five Non-euro countries experienced bottom extreme returns, with the Czech Republic having the most days (84) as the only country experiencing an extreme bottom return. On the other hand, from the top $10 \%$ distribution, all Euro-periphery countries experienced an extreme top return on 40 days. There are a total of 91 days during which five Euro-core countries experienced extreme top returns. On a total of 28 days, all Non-euro countries had an extreme top return, with the Czech Republic once more having the most days (95) with extreme top returns.

The graphical illustrations of bottom extreme return counts for the three groups appear in the following Figure:

Insert Figure 1 here

It is obvious that extreme bottom returns have a much higher density in the crisis periods. What we observe is: "bottom extreme returns clustering", since as one would expect most of the extreme bottom returns fall within the crisis periods. This happens for all the three (3) groups of the fifteen (15) European countries we study, and provides a visual confirmation of the quantitative result we found as far as the intensification of extreme returns is concerned.

The methodology of Bae et al. (2003) can be applied to study two types of spill-over effects: within groups and across groups. In this paper we mainly focus on effects across groups. 


\subsection{Examining the presence of extreme returns transmission}

In order to capture the effects within a group we consider a polychotomous variable, like Bae et al. (2003) and Boyson et al. (2010). The multinomial logistic regression models are widely used, and their theory and derivations are extensively mentioned in Hosmer Jr and Lemeshow (2004). These models are a modification of dichotomous (or binary) logistic regression models. The multinomial logistic regression models capture the case where the outcome variable is nominal with a number of levels that is larger than two. For example, such a model could study the choice of a health plan for the employees of a corporation, if each employee is asked to choose one among three different plans offered to them. The goal of these models is to estimate the probability of having each of the three plans, as a function of the covariates. If $P_{i}$ is the probability of an event $\mathrm{i}$ out of $\mathrm{m}$ possible event categories, a multinomial distribution can be defined by

$$
P_{i}=\frac{G\left(\beta_{i}^{\prime} x\right)}{1+\sum_{j=1}^{m-1} G\left(\beta_{j}^{\prime} x\right)}
$$

where $\mathrm{x}$ is the vector of covariates and $\beta_{i}$ the vector of coefficients associated with the covariates. The variable $\mathrm{j}$ takes into account the number of different event categories ( $\mathrm{m}$ in total). The function $G\left(\beta_{i}^{\prime} x\right)$ typically takes the form of an exponential function $\exp \left(\beta_{i}^{\prime} x\right)$, in which case Equation 1 represents a multinomial logistic (or multinomial logit) model. Such models are estimated using maximum likelihood, with the log-likelihood function for a sample of n observations given by

$$
\log L=\sum_{i=1}^{n} \sum_{j=1}^{m} I_{i j} \log P_{i}
$$

where $I_{i j}$ is a binary variable that equals one if observation i belongs in category $\mathrm{j}$, and zero otherwise. In this case, $\mathrm{i}$ takes values from 1 to $\mathrm{n}$ ( $\mathrm{n}$ is equal to the number of observations), while $\mathrm{j}$ takes the values 0 to $\mathrm{m}$ ( $\mathrm{m}$ is equal to the number of categories). Such models are based on the theory developed in McFadden (1974), where goodness-of-fit is calculated using the pseudo $-R^{2}$ approach. In this approach, the unrestricted (full model) likelihood, $L_{\Omega}$, and restricted (constants only) likelihood, $L_{\omega}$, functions are compared:

$$
\text { pseudo }-R^{2}=1-\left[\log L_{\omega} / \log L_{\Omega}\right]
$$

To capture the range of possible outcomes, and yet have a concrete model, we have a total of six categories: $0,1,2,3,4$, and 5 extreme return counts. For a model that has only constants, m-1, or five parameters, need to be estimated. But for every covariate added to the model, such as the daily average exchange rate changes, five additional parameters need to be estimated, one for each outcome. 
The top and the bottom extreme returns are estimated separately. We calculate the probability of a count of a specific level, $P_{i}$, by evaluating the covariates at their unconditional values,

$$
P_{i}^{*}=\frac{\exp \left(\beta_{i}^{\prime} x^{*}\right)}{1+\sum_{j=1}^{m-1} \exp \left(\beta_{j}^{\prime} x^{*}\right)}
$$

where $x^{*}$ is the mean value of $x$. From $P_{i}^{*}$, as in Greene (2003), we calculate the marginal changes in the probabilities for given changes in the independent variables, to test whether these changes are statistically significant 11 .

In our case, we have a variable $Y_{t}$ that counts the number of extreme returns and takes the value i when extreme returns (top or bottom) occur for the same day in i stock market indices on day t. This variable is calculated separately for the Euro-core, the Euro-periphery, and the Non-euro groups. Then, in the multinomial logistic regression Equation $4 P_{i}$ is equal to $P\left(Y_{t}=i \mid x_{t}\right)$ where $Y_{t}=0,1,2, \ldots k$ is the extreme return count variable that is created for the Non-euro, and for each of the country groups we defined (Euro-periphery vs. Euro-core etc.). So, we have $\mathrm{k}=5$ for all three country groups, where $x_{t}$ is a vector of explanatory variables (covariates), on day t. In Equation 4 , the argument of the exponential part (representing the logistic function) is a function of the covariates $\left(x_{t}\right)$ and the coefficients (the betas). This function is a linear expression of the arguments. Let's call it $g_{i}(t)$. We will use this function (which will take different forms) to study both the "within" and "across" groups extreme returns effects.

\subsection{Effects within groups}

In this section, we study the three country groups to determine whether there exist effects within them. Each of these groups has its own set of covariates. In line with Bae et al. (2003) and Gropp et al. (2009), as independent variables incorporated in $g_{i}(t)$ we have the intercept, the conditional volatility of the group stock index at time $\mathrm{t}\left(h_{t}\right) \sqrt{12}$, the average exchange rate change (per US dollars) in the group $\left(e_{t}\right)$, the average short term $(\mathrm{ST})$ interest rate level in the group $\left(i_{t}\right)$ as a proxy for the interbank short term liquidity risk $\left[13\right.$, and the average long term (LT) spread change $\left(b_{t}\right)$ vis-à-vis

\footnotetext{
${ }^{11}$ To elaborate a little further on why it is crucial that marginal effects are calculated for such models, it is known that the coefficients of a multinomial logistic are obtained from comparing the probability of a given outcome with the base outcome. In our case, the outcome is 0 , in other words, no extreme returns in the group. Thus, the estimated coefficient for covariate $x_{13}$ for outcome 3 , which is $\beta_{13}$ and is the coefficient for the 1st covariate, calculated for the 3rd outcome, measures the probability of having an outcome equal to 3 ( 3 extreme returns in the group), instead of an outcome 0 (no extreme returns in the group), for a unit change in the covariate $x_{13}$. But in reality, there is also the possibility of having the outcome 2 instead of 0 for a unit change in covariate $x_{13}$. This is exactly why we need the marginal effects, to calculate the probabilities associated with a unitary covariate change in adjacent categories, and not taking as an alternative only the base outcome (0 in our study)

${ }^{12}$ The conditional volatility is estimated using an $\operatorname{EGARCH}(1,1)$ model to the equally-weighted group indexes.

${ }^{13}$ Short term interest rates are available in Datastream (3-month Interbank interest rates).
} 
Germany as a proxy for the sovereign risk chang $£^{14}$.

We include exchange rate changes following Bae et al. (2003) who find that when currencies fall on average (which means that $e_{i t}$ rises) extreme returns are more common. Thus, the logistic regression $G\left(\beta_{i}^{\prime} x\right)=\exp \left(g_{i}\left(x_{t}\right)\right)$ of equation 1 has the following form for $g_{i}\left(x_{t}\right)$ :

$$
g_{i}\left(x_{t}\right)=b_{0 i}+b_{1 i} h_{t}+b_{2 i} e_{t}+b_{3 i} i_{t}+b_{4 i} b_{t}
$$

where $\mathrm{i}=0,1,2,3,4,5$ for each country group, the extreme return count for the group. Equation 5 represents the inter-group effects formula for the three groups examined. For each group we calculate the equally weighted average group values, on a daily basis, of the conditional volatility $\left(h_{t}\right)$, the exchange rate change $\left(e_{t}\right)$, the short term interest rates levels $\left(i_{t}\right)$, and the long term spread change vis-à-vis Germany $\left(b_{t}\right)$.

We estimate these models for each group, for the entire sample and for each of the three time periods. It is worth noting that, in the second case, the extreme return counts are calculated separately for each of the three periods. In other words, in each of the three periods the bottom and top extreme values correspond to the respective $10 \%$ and $90 \%$ threshold points of each period. For the entire sample, we calculate the sum of the three subsamples (with three cutoffs). Otherwise, we would have observations in the subsamples that might not be in the entire sample (or vice versa). As a robustness test, we also calculated the entire sample using one cutoff (see Section 4). We first present in Table 3 the detailed findings for the Euro-periphery group for bottom extreme returns and for the entire period.

Insert Table 3 here

All the coefficients are the marginal effect: 15 . The probability that no Euro-periphery country has a bottom tail return is equal to $77.49 \%$. This is calculated as the fraction of the number of 0 extreme returns divided by the total days $\frac{1859}{2399}=0.774$. The coefficient $\beta_{01}$ corresponds to the event $\mathrm{Y}=1$, in other words the event where only one Euro-periphery country has an extreme return (an exceedance) on that day, and the probability of this event is calculated as $P_{1}=\frac{\exp \left(\beta_{01}\right)}{1+\sum_{i=0}^{5} \exp \left(\beta_{0 i}\right)}$. This probability is found to be equal to $12.3 \%$ (see baseline predicted probability of Table 3 , for column

\footnotetext{
${ }^{14}$ Spreads are calculated as the difference between the yield of the 10 year government bond of country i's debt and the yield of the 10 year German government bond. Naturally, for the Euro-core group, one of the five countries is Germany, so, for Germany, the LT Spread Change will be zero, but the other four Euro-core countries will have their respective LT daily spread change.

${ }^{15}$ There are 23 more Tables like Table 3 (24 in total - 12 for bottom and 12 for top extreme returns. We do not include them in this paper due to space constraints. These tables are available upon request.
} 
(1), i.e. for one bottom extreme return). If currencies in the group fall on average (in which case $e_{i t}$ rises), the probability of extreme returns increases, since the signs of the exchange rate marginal effects are positive, and statistically significant at the $5 \%$ level for the first exceedance, and at the $1 \%$ level for the coincidence of two, three, four and five bottom extreme returns. In their study Bae et al. (2003) measured returns in dollars and the fact that they came up with very similar results made them wonder whether the stock return contagion they measured was actually foreign exchange contagion. Thus, they also estimated their models in local currencies, but the results were similar to the dollar returns. But we estimate our models in local currencies from the beginning, so we do not face such an issue. The results for ST interest rates are mixed since two marginal effects are statistically significant, for the outcomes of one and five bottom counts in the group, but with contradictory signs. Regarding the LT spread change in the group vis-à-vis Germany, we find positive and statistically significant marginal effects. For all extreme bottom outcomes except for the second, the marginal effects are significant at the $1 \%$ level. The positive sign of the coefficient indicates that a $1 \%$ increase in the average Euro-periphery LT spread increases the probability of extreme bottom returns in the group. A change of $1 \%$ in the average LT spread of the Euro-periphery group, increases the probability of two bottom extreme returns by $14.7 \%$. To simplify the presentation, in Table 4 we show a summary for the within groups results, for the entire sample, and the three periods separately. The number of "+" (or "-") indicates the number of statistically significant (in the $1 \%$ or $5 \%$ levels) and positive (or negative) marginal effects.

Insert Table 4 here

Pre-crisis the effect of the covariates on the probability of extreme returns is rather weak, while the role of covariates increases significantly in the crisis periods in most of the cases. The results are even stronger when we take the extreme returns over the entire period which notably includes the US-crisis as well. The effect of volatility is somehow smaller in the Euro-crisis period compared to the Pre-crisis period, for the bottom tail. Exchange rate changes are not significant for the bottom count of the Non-euro group in the Pre-crisis period, with zero significant marginal effects, while they became significant in four of the five cases in the Euro-crisis period. Exchange rate changes have a positive coefficient for the bottom tail, and a negative coefficient for the top tail. This means that higher exchange rates (i.e. weaker currencies) lead to a higher probability of extreme bottom returns and a lower probability of extreme top returns. Average ST interest rates are not significant in most of the cases, while average LT spread changes become more significant in the Euro-crisis period, es- 
pecially for the Euro-core and the Euro-periphery group as far as the bottom tails are concerned, and the Non-euro and Euro-core groups for the top tail returns. For the bottom tail, higher average group LT spread changes (i.e. an increase in the average group sovereign risk) lead to higher probabilities of extreme group bottom returns, while they decrease the probability of extreme top returns.

In summary, the findings so far indicate a much tighter relationship between the fundamental factors (covariates) affecting the extreme stock market movements within each group during the Eurocrisis and US-crisis periods compared to the Pre-crisis period.

\subsection{Effects across groups}

Next we test for across-groups effects. This deals with the question of whether the number of extreme return counts in one group (the Euro-periphery group) can help predict the number of extreme returns in other groups (the Euro-core and the Non-euro groups). According to Bae et al. (2003) and Boyson et al. (2010), if a fraction of extreme returns in one group is unexplained by its own covariates, but can be explained by extreme returns in another area, this can be interpreted as evidence of transmission of the crisis across group ${ }^{16}$.

Our primary interest is to study for across-groups effects from the Euro-periphery group to the Non-euro and the Euro-core groups. To examine this question, we re-estimate the models of Table 4 for the Euro-core and Non-euro groups respectively, adding a covariate related to the extreme return count $\left(Y_{j t}^{*}\right)$ from the Euro-periphery. In this case the equations for the across groups examination take the following shape:

$$
g_{i}\left(x_{t}\right)=b_{0}+b_{1} h_{i t}+b_{2} e_{i t}+b_{3} i_{i t}+b_{4} b_{i t}+b_{5} Y_{j t}^{*}
$$

For example, to examine if the Euro-periphery group provokes transmission effects in the Euro-core group the dependent variable is the number of extreme returns in the Euro-core group and the first three covariates of the right hand side concern the Euro-core group, while the last covariate is related to the count of extreme returns of the Euro-periphery group on that day. The null hypothesis of no transmission effects can be rejected in case the coefficient of $Y_{j t}^{*}$ is found to be statistically significant.

In Table 5 we present the detailed across groups effects from the Euro-periphery extreme bottom returns to the Euro-core group for the entire period:

\footnotetext{
${ }^{16}$ In general, the definition of contagion is far from being simple and commonly accepted. Pericoli and Sbracia (2003) provide five of the most widely accepted definitions of financial contagion. According to one of their definitions "Contagion is a significant increase in the probability of a crisis in one country, conditional on a crisis occurring in another country." According to another of their definitions, "Contagion occurs when cross-country co-movements of asset prices cannot be explained by fundamentals". Hence, these definitions are consistent with Bae et al. (2003) and Boyson et al. (2010).
} 
Insert Table 5 here

The main variable of interest is the "Bottom Count Euro-periphery" variable, which is the $Y_{j t}^{*}$ in equation 12. We see that this variable is positive and significant for all five Euro-core bottom outcomes. In other words a higher value of bottom Euro-periphery extreme returns increases the probability of bottom extreme returns for the Euro-core group as well. For one more Euro-periphery country having extreme bottom returns, there is an increase of $7.8 \%$ in the probability of one Euro-core country having extreme bottom returns. Given the fact that the baseline predicted probability of one Euro-core country having an extreme bottom return is $6.9 \%$, this marginal effect is very significant both economically and statistically.

Table 6 reports the marginal effects of $Y_{j t}^{*}$ for all five extreme outcomes, for all groups and all periods:

Insert Table 6 here

The gray line corresponds to the gray line in Table 5. Indeed we see that the statistical significance of $Y_{j t}^{*}$ is very strong and quite stable throughout the entire period and the three subperiods (Pre-crisis, US-crisis and Euro-crisis). The marginal effects are quite significant, with one more Euro-periphery country having extreme bottom returns increasing by $9.8 \%$ the probability of one Non-euro country having extreme bottom returns in the Entire period, $10.5 \%$ in the Pre-crisis period, $10.5 \%$ in the US-crisis period and $6.4 \%$ in the Euro-crisis period. In some cases the coefficients intensify during the US-crisis: a $4.8 \%$ increase for two (2) Non-euro bottom extreme returns in the Pre-crisis period becomes $6.3 \%$ in the US-crisis, an $8.5 \%$ increase for the one (1) Euro-core bottom extreme return becomes $11 \%$ during the US-crisis et cetera. We notice that the marginal effects are sometimes lower in the Euro-crisis period (6.4\% instead of $10.5 \%, 3.6 \%$ instead of $6.3 \%, 1.3 \%$ instead of $2.6 \%$ for the Non-euro group for the outcomes of one, two and three bottom extreme returns). But one has to take into account that an extreme return is much more "extreme" during the Euro-crisis period compared to the Pre-crisis period, in terms of the magnitude of expected losses. We discuss this further later in this section.

Table 7 provides the summary results for the across groups effects, for the entire period and the three time periods we examine (the Pre-crisis, the US-crisis and the Euro-crisis periods) separately. 
The evidence supports the hypothesis that there are important (positive) effects from the Europeriphery to the other two groups. Extreme bottom (or top) return counts in the Euro-periphery group have a significant (and positive) impact on the extreme return counts of the Euro-core and Non-euro groups in most of the cases. The results are stronger for the entire sample period (which also includes the US-crisis) but the number of statistically significant coefficients does not change between the Pre-crisis and the crisis periods.

We use a few fundamental variabes to capture changes in fundamentals (short term rates, term structure etc.). A question that naturally comes to mind is which ones are more relevant and why? Under what conditions? Given the results of Table 7, one can see that in the Pre-crisis period, the effect of these variables was almost non-existent for the bottom extreme returns (zero significant marginal effects for the Non-euro group, one significant for the Euro-core). In the US-crisis period, the volatility appears to be significant for both the Non-euro and the Euro-core groups (two significant coefficients for both for the bottom extreme returns). The exchange rate change is significant for the Non-euro group, while it is insignificant for the Euro-core group. This is interesting given the fact that the Non-euro are not part of the Eurozone, which means that they have their own currencies. It is not clear why this is the case, but a possible explanation is due to the fact that the Euro-core countries are part of a monetary union, i.e. they share the same currency, which goes over and beyond every individual country. This is not the case for the Non-euro group, and this might be an explanation of why the marginal effects are significant for the Non-euro group but not for the Euro-core group. The probabilities of the Euro-core group do not appear to be affected by change in the Euro-USD exchange rate. Once more, the exchange rate change is significant for the Non-euro group during the Euro-crisis period, while again it is insignificant for the Euro-core group. Overall, the effect of the "Euro-periphery Bottom Extreme Count" appears to dominate the effect of the fundamental covariates. The only two exceptions is the volatility for the US-crisis period (for both groups) and the exchange rate change for the Non-euro group (both for the US-crisis and for the Euro-crisis periods). Once more, the by-and-large failure of fundamentals to affect extreme returns does not have an easy explanation. It seems to be that extreme returns are affected by other factors, the most significant of which (in this setting) is the number of Euro-periphery countries experiencing extreme returns on the same day.

Counting the number of statistically significant parameters provides an indication of the evolving dynamics of the transmission of extreme shocks from the Euro-periphery to the Non-euro and the 
Euro-core groups, but, to add rigor on top of this approach, we estimate the parameters on the three subsamples together, and then conduct likelihood ratio tests to see whether separate parameters for the subsamples are needed. The null hypothesis is that models under examination are nested to each other, which means that estimating separate parameters does not create a statistically significant improvement in the fit of the model. The null hypothesis is rejected in a statistical significance level $\alpha$ if:

$$
\text { Reject } H_{0} \text { if: } \mathrm{P} \text {-value }<\alpha
$$

In case the null hypothesis is rejected, the two models are not nested, which means that statistically significant differences exist between the examined subperiods. The results of the likelihood ratio tests appear in Table 8

Insert Table 8 here

The likelihood ratio test results of Tables 8 indeed confirm significant statistical differences of the relationships affecting bottom extreme returns count for almost all periods. We are testing all possible four (4) assumptions: 1) that the Pre-crisis, US-crisis and Euro-crisis models are nested in the Entire model, that the Pre-crisis and US-crisis period models are nested in the combined Pre-crisis and US-crisis models, that the US-crisis and Euro-crisis period models are nested in the combined US-crisis and Euro-crisis model, and that the Pre-crisis and Euro-crisis period models are nested in the combined Pre-crisis and Euro-crisis models. Since we are studying the across group effects on two groups (Euro-core and Non-euro), we have in total eight (8) different model specifications to compare. Interestingly, out of these eight (8) specifications, all models appear to have significantly changed (at least at the $5 \%$ level). Therefore, the evidence is strong that the relationships affecting bottom extreme returns have indeed changed during the three periods. Moreover, the absolute size of the effects is stronger since the same $10 \%$ cutoff values are higher during the crisis periods, as Table 9 shows:

Insert Table 9 here

In other words, even before the two crises there was a significant shock transmission channel from the Euro-periphery to the Euro-core and the Non-euro, but the shocks became deeper in terms of the expected losses for all groups, indicating an intensification of the effects in terms of the actual stock 
market losses they incur. Studying only the coefficients of the extreme returns during the three periods can be misleading in the sense that the underlying extreme returns are sometimes significant higher in the crisis periods, which means the expected losses are significantly higher, a fact that should not be neglected. This is also verified by the average returns on the days with extreme bottom outcomes which appear on Table 10 :

Insert Table 10 here

Indeed, one can easily compare the Pre-crisis with the crisis periods and see the evident intensification of extreme bottom returns. For example, the average return on days where four (4) Non-euro country had an extreme bottom return (column 4) is $-1.694 \%$ in the Pre-crisis period, while it decreases to $-3.346 \%$ in the US-crisis and to $-2.565 \%$ in the Euro-crisis period. For the outcome where all five (5) Euro-core countries had an extreme bottom return on the same day (column 5) the average return decreased from $-1.776 \%$ in the Pre-crisis to $-4.236 \%$ in the US-crisis and to $-2.802 \%$ in the Euro-crisis period. Thus, an "extreme bottom return" in the Euro-crisis period, is much more intense than an "extreme bottom return" in the Pre-crisis period. Although the percentile does not change ( $10 \%$ of the marginal distribution in both periods), the actual returns themselves are much more negative. This results in higher expected losses for investors in the occurrence of an "extreme event" (which by definition happens in 10\% of the days for all countries). Given the fact that stock market capitalizations in these country groups are trillions of Euros, a $1 \%$ or $2 \%$ increase in extreme bottom returns (in crisis periods) can lead to aggregate losses of tens of billions Euros in one single trading day.

\subsection{The joint dynamics of returns}

It is possible that linkages in countries that are part of the core Eurozone or the periphery are such that there should be higher transmission of shocks, and possibly different returns dynamics. Countries in the Eurozone (core) might be linked via a different mechanism than possibly countries that are outside this zone. One possible explanation has to do with Euro core holdings of debt of the periphery countries or via trade linkages.

For a formal way to compare the coefficients, we use a series of t-tests, the results of which appear in Table 11:

Insert Table 11 here 
The table provides a total of thirty (30) coefficients comparison, fifteen (15) for each of the two regions effects (Periphery to Core, Periphery to Eu), five for every combination of periods (Pre-crisis/UScrisis, Pre-crisis/Euro-crisis, US-crisis/Euro-crisis, Pre-crisis/US-crisis, Pre-crisis/Euro-crisis, US-crisis/ Euro-crisis). Regarding the "Periphery To Core" hypothesis: the null hypothesis that the two coefficients are equal is rejected for all five cases in the Pre-crisis/US-crisis comparison (at least in the $5 \%$ significance level), which means that coefficients between these two periods are significantly different from each other. Regarding the Pre-crisis/US-crisis periods comparison, the coefficients are difference for the three bottom extreme returns outcome, while regarding the US-crisis/Euro-crisis period comparison, the coefficients are significantly different in three cases: the one (1), two (2) and four (4) bottom extreme returns. As far as the "Periphery To Eu" outcome is concerned, four (4) out of five (5) coefficients are significantly different for the Pre-crisis/US-crisis periods (the coefficients of one, two, three and four bottom extreme returns), while two coefficients are significantly different when comparing the Pre-crisis/Euro-crisis period (three and four bottom extreme returns). Finally, all five (5) coefficients are significantly different for the US-crisis/Euro-crisis periods comparison.

\subsection{A Vector Autoregression (VAR) specification}

In order to examine the presence of lagged relationships among the stock market returns of the Euro-periphery and the other two groups (Euro-core and Non-euro), we use a Vector Autoregression (VAR) model which consists of a set of I endogenous variables $y_{t}=\left(y_{1 t}, \ldots, y_{i t}, \ldots, y_{I t}\right)$ for $\mathrm{i}=1, \ldots \mathrm{I}$. In our case, $\mathrm{I}=6$ and the variables are the ones previously used for the groups: the Euro-periphery stock returns, the exchange rate changes, the short term interest rate, the bond spread change, the volatility and each group's stock returns, as defined and explained in Section 3.3. A VAR(k)-process is defined as:

$$
y_{t}=A_{1} y_{t-1}+\ldots+A_{p} y_{t-p}+u_{t}
$$

with $A_{l}$ being $(I x I)$ coefficient matrices for $\mathrm{l}=1, \ldots, \mathrm{k}$ and $u_{t}$ being a I-dimensional process with $E\left(u_{t}\right)=0$ (white noise). For our analysis, we choose $\mathrm{k}=5$, i.e. we incorporate 5 daily lagged values for every variable. The VAR models are separately estimated for the three sub-periods (Pre-crisis, US,crisis, Euro-crisis). The results follow in Table 12 .

Insert Table 12 here 
Even though all variables are included in the VAR models, only the coefficients of Periphery Returns are reported, due to space constraints. In the six VAR models that are estimated, there do not appear to exist significant lag relationships among the Euro-periphery group and the other two groups. The only exception is the Euro-core group for the US-crisis period, in which case the coefficients of one (1), three (3), and five (5) days are significant (Periphery Return $n_{t-1}$, Periphery Return $n_{t-3}$, Periphery Return $_{t-5}$ ). In two of these three cases (Periphery Return $n_{t-1}$ and Periphery Return P $_{t-5}$ ) the coefficients are negative, which means that a lower Euro-periphery return one and five days before, is associated with lower Euro-core returns in the current day. The coefficient of three days is positive, which can be interpreted as a reversal effect. The coefficients for the two remaining days (two and four) are negative, but insignificant. It seems to be the case that markets are absorbing the shocks of extreme returns on a daily basis, as our previous results (Section 3.4) have shown.

\subsection{Dynamic conditional correlation (DCC) specification}

Another approach that might provide some additional insight to our analysis, are the class of models that study time varying conditional volatility. One class of such models are the dynamic conditional correlation (DCC) models which were introduced in Engle (2002). In these models, the conditional correlations are allowed to follow a process which is similar to a $\operatorname{GARCH}(1,1)$ :

$$
h_{i j, t}=\rho_{i j, t} \sqrt{h_{i i, t} h_{j j, t}}
$$

where the $\rho$ parameters follow a dynamic process. The DCC model can be written as:

$$
\begin{aligned}
y_{t} & =C x_{t}+\epsilon_{t} \\
\epsilon_{t} & =H_{t}^{1 / 2} v_{t} \\
H_{t} & =D_{t}^{1 / 2} R_{t} D_{t}^{1 / 2} \\
R_{t} & =\operatorname{diag}\left(Q_{t}\right)^{-1 / 2} Q_{t} \operatorname{diag}\left(Q_{t}\right)^{-1 / 2} \\
Q_{t} & =\left(1-\lambda_{1}-\lambda_{2}\right) R+\lambda_{1} \widetilde{\epsilon_{t-1}}{\widetilde{\epsilon_{t-1}}}^{\prime}+\lambda_{2} Q_{t-1}
\end{aligned}
$$

In the above equations, $y_{t}$ is a vector of dependent variables, $\mathrm{C}$ is the parameter matrix, $x_{t}$ is a vector of independent variables (which can also be lagged). $H_{t}^{1 / 2}$ is the Cholesky factor of time-varying conditional covariance matrix $H_{t}$ and $v_{t}$ is the vector of zero-mean, unit variance independent and identically distributed (i.i.d.) innovations. $D_{t}$ is a diagonal matrix of conditional variances, $R_{t}$ is a matrix of conditional quasicorrelations, and $\widetilde{\epsilon_{t}}$ is a vector of standardized residuals, $D_{t}^{-1 / 2} \epsilon_{t}$. R is the 
weighted average of the unconditional VCE of the standardized residuals and the unconditional mean of $Q_{t}$.

These models are extentions of the Autoregressive Conditional Heteroskedasticity (ARCH) models. In particular, the DCC use the GARCH $(1,1)$ model:

$$
h_{t}=\alpha_{0}+\alpha_{1} u_{t-1}^{2}+\gamma_{1} h_{t-1}
$$

which involves a lag of both the $\mathrm{ARCH}\left(u_{t-1}\right.$, which corresponds to the innovation) and the conditional variance terms $\left(h_{t-1}\right)$.

The results follow in Table 13 .

Insert Table 13 here

The lagged coefficients of Periphery Returns are insignificant both for the effect to the Euro-core and for the effects to the Non-euro groups (positive during the Pre-crisis, negative during the UScrisis, one positive and one negative during the Euro-crisis). The only exception is the coefficient of Periphery Returns $s_{t-1}$ during the Euro-crisis, which is positive and significant at the $10 \%$ level. This is an indication of a reversal effect on the following day. In unreported results, all coefficients of Periphery Returns are positive and significant at the $1 \%$ level, which verify the results of Section 3.4 . The strong presence of $\mathrm{ARCH}$ and GARCH effects is established given that the coefficients of these terms are positive and statistically significant at the $1 \%$ level.

\subsection{The effect of a shock originating from the United States}

Given the fact that our sample contains the US crisis period, extreme returns in the Euro-periphery group countries and in other European countries can be due to a shock originating from the US. To address these concerns, we estimate the following models, which assess the impact of extreme stock returns from the US:

$$
g_{i}\left(x_{t}\right)=b_{0}+b_{1} h_{i t}+b_{2} e_{i t}+b_{3} i_{i t}+b_{4} b_{i t}+b_{5} Y_{j t}^{*}+b_{6} Y_{U S A, t}+b_{7} Y_{U S A, t-1}
$$

where $Y_{U S A, t}$ and $Y_{U S A, t-1}$ take the value one (1) if the USA had an extreme bottom stock return in day t, and day t-1 respectively. The reason why we include both $t-1$ and $t$ in our analysis, is due to the fact that the European and the US stock markets do not operate on the same time frame. There actually is some overlap between Europe's trading at day t (and this is why we incorporate the 
parameter $Y_{U S A, t}$ ), but the US stock market stays open quite a few hours after the European stock markets are closed for the day. Thus, the effect of price movements of day $t$ in the US stock market, might affect the European stock markets in day $t+1$. The analysis includes all the covariates, but we only report the effect of extreme botton counts, since these coefficients are of primary importance, and due to space constraints. The results of this analysis appear in Table 14 .

Insert Table 14 here

Indeed, the effect of the USA appears to be strong and significant in most cases. In particular, as far as the "Periphery to Core" effect is concerned, the effect of a USA extreme stock return (on day t) is significant in four out five bottom outcomes (on day t) for the Euro-core group in the US-crisis and the Euro-crisis. The lagged effect is significant in two ouf five cases for the Euro-core group in the US-crisis period, and in three out ouf five cases in the Euro-crisis period. As far as the Non-euro group is concerned, the day t effect is significant in three out of five cases for the US-crisis period, and in three out of five cases in the Euro-crisis period. The lagged USA effect (day t-1) is insignificant in the US-crisis period, while it is significant in three out of five outcomes in the Euro-crisis period.

What is most important here is that the inclusion of a contemporaneous and lagged extreme return count for the USA, erases the Euro-periphery effect for the Pre-crisis period for the Euro-core group, but does not erase the effect for the US-crisis and the Euro-crisis periods. The Euro-periphery effect is significant in all five bottom outcomes for the US-crisis period, and in four out of five outcomes for the Euro-crisis period as far as the Euro-core group is concerned. As far as the Non-euro group is concerned, the effect is significant in three out of five bottom outcomes in the Pre-crisis period, five out of five for the US-crisis period, and three out five for the Euro-crisis period. All in all, our results show that indeed the Euro-periphery bottom extreme return count has a significant effect on the extreme bottom returns of the Euro-core and the Non-euro group, even when controlling for the extreme US stock returns.

\subsection{Extreme Return Response Curve}

Another question that is interesting to study, is whether the occurrence of four (4) or five (5) extreme returns in the Euro-periphery group, is associated with an increase in the probability of four (4) or five (5) extreme returns in other groups. In the spirit of what Bae et al. (2003) call "Coexceedance Response Curves", we calculate the probabilities of extreme returns for the Euro-core bottom returns, vis-à-vis the Euro-periphery bottom extreme returns. The results appear in Figure2. 
Insert Figure 2 here

Indeed, there appears to be a strong and direct association between the occurrence of extreme bottom returns in the Euro-periphery group, and the probabilities of extreme returns in the Euro-core group. The first of the six sub-figures, shows the probability of zero (0) Euro-core extreme bottom returns, vis-à-vis the occurrence of all possible extreme bottom events for the Euro-periphery group $(0,1,2,3,4,5)$. The probability of having zero (0) extreme bottom returns at the Euro-core group is over $90 \%$ in case of zero (0) Euro-periphery extreme bottom returns. The probability of the event falls as the Euro-periphery extreme bottom return count increases, reaching a value of approximately $5 \%$ in the all five Euro-periphery countries experience an extreme bottom return. For one Euro-core extreme bottom count, the probability peaks at three bottom Euro-periphery extreme returns (greater than 15\%). For two Euro-core extreme bottom returns, the probability peaks at three Euro-periphery extreme bottom returns (4\%). For three Euro-core extreme bottom returns, the probability peaks at four Euro-periphery extreme bottom returns (approximately 30\%). The probability for four Eurocore extreme bottom returns, the probability reaches its highest level for four Euro-periphery extreme bottom returns (20\%), and, finally, the probability of having five Euro-core bottom extreme returns is at its highest level when all five Euro-periphery countries are experiencing extreme bottom returns.

\section{Robustness and alternative specifications}

To verify the robustness of our results, as a first robustness check, instead of $10 \%$ and $90 \%$ extreme returns cutoffs, we used the $5 \%$ and $95 \%$ percentages. The results are robust in this change. Furthermore as a second robustness check, instead of the raw returns, we calculated extreme returns on the standardized residuals of a $\operatorname{GARCH}(1,1)$ model, accounting for the time-varying volatility effects, since in periods of high volatility, extreme returns are more probable. In order to calculate the volatility, we move in line with Christiansen and Ranaldo (2009), estimating a AR(1)-GARCH(1,1) model for each group's average returns:

$$
\operatorname{Ret}_{t}^{\text {group }}=c_{0}+c_{1} \operatorname{Ret}_{t-1}^{\text {group }}+\epsilon_{t}
$$

where $\epsilon_{t} N\left(0, \sigma_{t}^{2}\right)$ and the variance follows a $\operatorname{GARCH}(1,1)$ process:

$$
\sigma_{t}^{2}=c_{2}+c_{3} \sigma_{t-1}^{2}+c_{4} \epsilon_{t-1}^{2}
$$


The volatilities are then obtained as the estimated $\hat{\sigma_{t}}$ from the $\mathrm{AR}(1)-\mathrm{GARCH}(1,1)$ model. We notice that for the extreme returns counts filtered by a GARCH the effect of volatility is not significant (for the raw returns all volatility coefficients were found to be positive and statistically significant - in other words an increase in volatility increases the probability of extreme bottom returns).

As a final robustness check, we re-estimated the models for the Entire period, using one cutoff, instead of separate cutoffs for the subperiods.

The results are found to be robust when compared with the results of the three cutoffs previously examined 17

\section{Conclusion}

We examine the transmission of financial shocks among three groups of countries: the Europeriphery countries (Portugal, Ireland, Italy, Greece, Spain), the Euro-core countries (Germany, France, the Netherlands, Finland, Belgium), and the major European Union -but not euro- countries (Sweden, UK, Poland, Czech Republic, Denmark), using daily stock market data from January 2004 until March 2013. The entire period is further split in three sub periods, the Pre-crisis pe$\operatorname{riod}(1 / 1 / 2004-26 / 2 / 2007)$, the US-crisis period (27/2/2007-7/12/2009) and the Euro-crisis period $(8 / 12 / 2009-13 / 3 / 2013)$. The creation of the three groups is justified by the existence of the European Union (which is mainly a free trade area), and the Eurozone (monetary union). The five Euro-periphery countries were the most badly hit during the recent crises periods, Our analysis is split in two parts: the first part concerns extreme stock index returns, controlling for various fundamentals derived from financial market data (volatility, exchange rate change, short interest rates, long term spread change). We find that even before the two crises periods there was a significant shock transmission channel from the Euro-periphery to the Euro-core and the Non-euro groups. During the crises the shocks transmitted were more substantial. Thus, expected losses from extreme returns have increased in the crises periods, being evidence of an intensification of the effects during the recent financial crises. The fact that indeed the models in the different periods exhibit differences is verified using likelihood ratio tests.

The implications of the overall findings are quite significant for investors who may want to diversify their portfolios, and they should be aware of the stock indices movement dynamics and of how extreme shocks propagate from one group of countries to the others, thus affecting their portfolios' overall risk profiles. Furthermore, the findings would be useful for policy makers in order to assess policy decision making in times of extreme shocks (such as crisis periods). The fact that the European

\footnotetext{
${ }^{17}$ The results are available upon request.
} 
financial markets affect one another provides evidence that a failure to properly confront crisis could see the propagation and clustering of extreme returns, leading to significant losses for investors and institutions. Future research could also take into account different models or move in the direction of studying higher frequency (intraday) financial markets dynamics. 


\section{References}

Abad, P., Chuliá, H., Gómez-Puig, M., 2014. Time-varying integration in european government bond markets. European Financial Management 20, 270-290.

Allen, F., Gale, D., 2000. Financial contagion. Journal of Political Economy 108, 1-33.

Aït-Sahalia, Y., Cacho-Diaz, J., Laeven, R. J., 2010. Modeling financial contagion using mutually exciting jump processes. Working Paper 15850, National Bureau of Economic Research.

Bae, K.-H., Karolyi, G. A., Stulz, R. M., 2003. A new approach to measuring financial contagion. Review of Financial studies 16, 717-763.

Banerjee, A., Hung, C.-H. D., Lo, K. L., 2015. An anatomy of credit risk transfer between sovereign and financials in the eurozone crisis. Journal of International Financial Markets, Institutions and Money .

Bekaert, G., Harvey, C. R., Ng, A., 2005. Market integration and contagion. The Journal of Business $78,39-69$.

Bhanot, K., Burns, N., Hunter, D., Williams, M., 2012. Was there contagion in eurozone sovereign bond markets during the greek debt crisis? Working Paper WP 006FIN-73-2012, The University of Texas at San Antonio, College of Business.

Boyson, N. M., Stahel, C. W., Stulz, R. M., 2010. Hedge fund contagion and liquidity shocks. The Journal of Finance 65, 1789-1816.

Caporin, M., Pelizzon, L., Ravazzolo, F., Rigobon, R., 2013. Measuring sovereign contagion in europe. Tech. rep., National Bureau of Economic Research.

Caselli, S., Gandolfi, G., Soana, M. G., 2014. The impact of sovereign rating news on european banks. European Financial Management .

Chan-Lau, J. A., Liu, E. X., Schmittmann, J. M., 2015. Equity returns in the banking sector in the wake of the great recession and the european sovereign debt crisis. Journal of Financial Stability $16,164-172$.

Chouliaras, A., Grammatikos, T., 2015. News flow, web attention and extreme returns in the european financial crisis .

Christiansen, C., 2014. Classifying returns as extreme: European stock and bond markets. International Review of Financial Analysis 34, 1-4. 
Christiansen, C., Ranaldo, A., 2009. Extreme coexceedances in new eu member states' stock markets. Journal of banking \& finance 33, 1048-1057.

Corsetti, G., Pericoli, M., Sbracia, M., 2005. 'some contagion, some interdependence': More pitfalls in tests of financial contagion. Journal of International Money and Finance 24, 1177 - 1199.

Doukas, J., 2012. Editorial: Can the euro survive? European Financial Management 18, 321-323.

Doukas, J., 2013. Editorial: Another euro peril: Eu current account imbalances. European Financial Management 19, 1-3.

Dungey, M., Fry, R., González-Hermosillo, B., Martin, V. L., 2005. Empirical modelling of contagion: a review of methodologies. Quantitative Finance 5, 9-24.

Engle, R., 2002. Dynamic conditional correlation: A simple class of multivariate generalized autoregressive conditional heteroskedasticity models. Journal of Business \& Economic Statistics 20, 339-350.

Fabozzi, F. J., Giacometti, R., Tsuchida, N., 2016. Factor decomposition of the eurozone sovereign cds spreads. Journal of International Money and Finance 65, 1-23.

Featherstone, K., 2011. The jcms annual lecture: The greek sovereign debt crisis and emu: A failing state in a skewed regime*. JCMS: Journal of Common Market Studies 49, 193-217.

Forbes, K. J., Rigobon, R., 2001. No contagion, only interdependence: Measuring stock market comovements. Journal of Finance 57, 2223-2261.

Greene, W. H., 2003. Econometric analysis. Pearson Education India.

Gropp, R., Duca, M. L., Vesala, J., 2009. Cross-border bank contagion in europe. International Journal of Central Banking 5, 97-139.

Gündüz, Y., Kaya, O., 2014. Impacts of the financial crisis on eurozone sovereign cds spreads. Journal of International Money and Finance 49, 425-442.

Haß, L. H., Koziol, C., Schweizer, D., 2014. What drives contagion in financial markets? liquidity effects versus information spill-over. European Financial Management 20, 548-573.

Hosmer Jr, D. W., Lemeshow, S., 2004. Applied logistic regression. John Wiley \& Sons.

Kaminsky, G. L., Reinhart, C., Vegh, C. A., 2003. The unholy trinity of financial contagion. Working Paper 10061, National Bureau of Economic Research. 
Lucey, B., Sevic, A., 2010. Investigating the determinants of banking coexceedances in europe in the summer of 2008. Journal of International Financial Markets, Institutions and Money 20, 275-283.

Markwat, T., Kole, E., van Dijk, D., 2009. Contagion as a domino effect in global stock markets. Journal of Banking \& Finance 33, 1996 - 2012, financial Globalisation, Risk Analysis and Risk Management.

McFadden, D., 1974. The measurement of urban travel demand. Journal of public economics 3, 303328.

Metiu, N., 2012. Sovereign risk contagion in the eurozone. Economics Letters 117, 35-38.

Missio, S., Watzka, S., 2011. Financial contagion and the european debt crisis. CESifo Working Paper Series 3554, CESifo Group Munich.

Mollah, S., Quoreshi, A. S., Zafirov, G., 2016. Equity market contagion during global financial and eurozone crises: Evidence from a dynamic correlation analysis. Journal of International Financial Markets, Institutions and Money .

Pericoli, M., Sbracia, M., 2003. A primer on financial contagion. Journal of Economic Surveys 17, $571-608$.

Rigobon, R., 2002. Contagion: How to Measure It?, University of Chicago Press, pp. 269-334.

Thomadakis, A., 2012. Measuring financial contagion with extreme coexceedances. Tech. rep., School of Economics, University of Surrey. 
Table 1: Descriptive Statistics and Correlations for Stock Indices

\begin{tabular}{|c|c|c|c|c|c|c|c|c|c|}
\hline \multicolumn{10}{|c|}{ Panel A: Descriptive Statistics } \\
\hline & \multicolumn{3}{|c|}{$\begin{array}{c}\text { Pre-crisis } \\
1 / 1 / 2004-26 / 2 / 2007\end{array}$} & \multicolumn{3}{|c|}{$\begin{array}{c}\text { US-crisis } \\
27 / 2 / 2007-7 / 12 / 2009\end{array}$} & \multicolumn{3}{|c|}{$\begin{array}{c}\text { Euro-crisis } \\
8 / 12 / 2009-13 / 3 / 2013\end{array}$} \\
\hline & Non-euro & Euro-periphery & Euro-core & Non-euro & Euro-periphery & Euro-core & Non-euro & Euro-periphery & Euro-core \\
\hline Mean (\%) & 0.101 & 0.089 & 0.081 & -0.024 & -0.074 & -0.049 & 0.030 & -0.016 & 0.030 \\
\hline Median (\%) & 0.142 & 0.104 & 0.108 & 0.013 & 0.008 & 0.013 & 0.0544 & 0.015 & 0.052 \\
\hline Std. Dev. $(\%)$ & 0.715 & 0.569 & 0.703 & 1.616 & 1.555 & 1.619 & 0.952 & 1.284 & 1.189 \\
\hline Minimum (\%) & -4.514 & -3.405 & -3.338 & -8.809 & -8.118 & -7.618 & -4.467 & -4.929 & -5.081 \\
\hline Maximum (\%) & 3.441 & 2.790 & 2.858 & 8.689 & 7.838 & 8.584 & 5.321 & 9.118 & 6.848 \\
\hline \multicolumn{10}{|c|}{ Panel B: Correlations } \\
\hline & & \multicolumn{2}{|c|}{$\begin{array}{c}\text { Pre-crisis } \\
1 / 1 / 2004-26 / 2 / 2007\end{array}$} & \multicolumn{3}{|c|}{$\begin{array}{c}\text { US-crisis } \\
27 / 2 / 2007-7 / 12 / 2009\end{array}$} & & \multicolumn{2}{|c|}{$\begin{array}{c}\text { Euro-crisis } \\
8 / 12 / 2009-13 / 3 / 2013\end{array}$} \\
\hline Non-euro & $\begin{array}{r}\text { Non-euro } \\
1.000\end{array}$ & Euro-periphery & Euro-core & $\begin{array}{r}\text { Non-euro } \\
1.000\end{array}$ & Euro-periphery & Euro-core & $\begin{array}{r}\text { Non-euro } \\
1.000\end{array}$ & Euro-periphery & Euro-core \\
\hline Euro-periphery & 0.791 & 1.000 & & 0.919 & 1.000 & & 0.836 & 1.000 & \\
\hline Euro-core & 0.806 & 0.870 & 1.000 & 0.912 & 0.928 & 1.000 & 0.926 & 0.876 & 1.000 \\
\hline
\end{tabular}

Note: European countries are split in three groups: the Euro-periphery countries (Portugal, Ireland, Italy, Greece, Spain), the Euro-core countries (Germany, France, Finland, the Netherlands, Belgium) and the European Union -non Euro- countries (Poland, Czech Republic, Sweden, UK, Denmark). Country group log returns and standard deviations are calculated on the equally weighted mean portfolio of the country stock market daily returns for each group. 
Table 2: Counts of extreme bottom (and top) log returns for daily country group stock indices, January 1st 2004 to March 13th 2013.

\begin{tabular}{|c|c|c|c|c|c|c|c|c|c|c|c|c|c|c|}
\hline & \multirow{2}{*}{$\begin{array}{l}\text { Mean return }(\%) \\
\text { when } i=5\end{array}$} & \multicolumn{6}{|c|}{ Number of bottom counts } & \multicolumn{6}{|c|}{ Number of top counts } & \multirow{2}{*}{$\begin{array}{l}\text { Mean return }(\%) \\
\text { when } i=5\end{array}$} \\
\hline & & 5 & 4 & 3 & 2 & 1 & 0 & 0 & 1 & 2 & 3 & 4 & 5 & \\
\hline \multicolumn{15}{|l|}{ Non-euro } \\
\hline POL & -3.446 & 55 & 41 & 38 & 49 & 57 & 1847 & 1783 & 82 & 47 & 40 & 43 & 28 & 3.653 \\
\hline SWE & -3.727 & 55 & 45 & 54 & 54 & 32 & 1847 & 1783 & 42 & 56 & 61 & 53 & 28 & 4.025 \\
\hline CZE & -3.828 & 55 & 27 & 28 & 46 & 84 & 1847 & 1783 & 95 & 57 & 31 & 29 & 28 & 4.022 \\
\hline UK & -3.241 & 55 & 52 & 60 & 43 & 30 & 1847 & 1783 & 37 & 56 & 62 & 57 & 28 & 3.572 \\
\hline DEN & -3.370 & 55 & 47 & 48 & 42 & 48 & 1847 & 1783 & 61 & 42 & 55 & 54 & 28 & 3.382 \\
\hline Subtotal & & 55 & 53 & 76 & 117 & 251 & 1847 & 1783 & 317 & 129 & 83 & 59 & 28 & \\
\hline \multicolumn{15}{|c|}{$\begin{array}{l}\text { Euro- } \\
\text { periphery }\end{array}$} \\
\hline POR & -3.253 & 54 & 66 & 44 & 39 & 37 & 1859 & 1817 & 61 & 45 & 34 & 60 & 40 & 3.008 \\
\hline IRE & -3.944 & 54 & 54 & 26 & 50 & 56 & 1859 & 1817 & 69 & 47 & 31 & 53 & 40 & 3.522 \\
\hline ITA & -3.636 & 54 & 69 & 45 & 52 & 20 & 1859 & 1817 & 20 & 62 & 56 & 62 & 40 & 3.678 \\
\hline GRE & -4.160 & 54 & 35 & 22 & 23 & 106 & 1859 & 1817 & 108 & 32 & 20 & 40 & 40 & 4.200 \\
\hline SPA & -3.503 & 54 & 64 & 49 & 44 & 29 & 1859 & 1817 & 29 & 56 & 54 & 61 & 40 & 3.652 \\
\hline Subtotal & & 54 & 72 & 62 & 104 & 248 & 1859 & 1817 & 287 & 121 & 65 & 69 & 40 & \\
\hline \multicolumn{15}{|c|}{ Euro-core } \\
\hline GER & -2.855 & 109 & 44 & 32 & 19 & 36 & 1970 & 1938 & 46 & 25 & 31 & 47 & 91 & 2.530 \\
\hline FRA & -3.137 & 109 & 56 & 46 & 19 & 10 & 1970 & 1938 & 13 & 35 & 41 & 60 & 91 & 2.842 \\
\hline NL & -3.169 & 109 & 51 & 37 & 22 & 21 & 1970 & 1938 & 20 & 27 & 50 & 52 & 91 & 2.782 \\
\hline FIN & -3.303 & 109 & 38 & 24 & 19 & 50 & 1970 & 1938 & 48 & 26 & 26 & 49 & 91 & 3.240 \\
\hline BEL & -2.809 & 109 & 35 & 32 & 27 & 37 & 1970 & 1938 & 51 & 29 & 29 & 40 & 91 & 2.534 \\
\hline Subtotal & & 109 & 56 & 57 & 53 & 154 & 1970 & 1938 & 178 & 71 & 59 & 62 & 91 & \\
\hline
\end{tabular}

Note: Extreme returns for daily stock index top (bottom) log returns are the ones belonging to the highest (lowest) $10 \%$ of all daily returns. The extreme counts are defined as the joint occurrence of extreme returns across different country indexes on the same day. For example, out of a total sample of 2399 trading days, there are 104 days where exactly two Euro-periphery countries had extreme bottom returns on the same day, and in 23 of those days Greece is the one of the two countries having extreme bottom returns. 
Table 3: Within the Euro-periphery group bottom extreme counts of log returns for the entire period. The bottom extreme counts for the entire period are calculated as the sum of the bottom extreme counts for the three subperiods. All reported coefficients are marginal effects.

\begin{tabular}{lccccc}
\hline & $(1)$ & $(2)$ & $(3)$ & $(4)$ & $(5)$ \\
& Margin / SE & Margin / SE & Margin / SE & Margin / SE & Margin / SE \\
\hline Constant & $-0.157^{* * *}$ & $-0.103^{* * *}$ & $-0.085^{* * *}$ & $-0.067^{* * *}$ & $-0.066^{* * *}$ \\
& $(0.017)$ & $(0.011)$ & $(0.009)$ & $(0.009)$ & $(0.009)$ \\
Volatility & 0.014 & 0.006 & $0.008^{*}$ & $0.015^{* * *}$ & $0.012^{* * *}$ \\
& $(0.013)$ & $(0.007)$ & $(0.005)$ & $(0.003)$ & $(0.003)$ \\
Exchange Rate Change & $0.043^{* * *}$ & $0.024^{* * *}$ & $0.010^{* *}$ & $0.012^{* * *}$ & $0.009^{* * *}$ \\
& $(0.011)$ & $(0.006)$ & $(0.004)$ & $(0.003)$ & $(0.003)$ \\
ST Interest Rate & $-0.009^{*}$ & 0.001 & 0.002 & -0.001 & $0.004^{* * *}$ \\
& $(0.005)$ & $(0.003)$ & $(0.002)$ & $(0.002)$ & $(0.001)$ \\
LT Spread Change & 0.065 & $0.147^{* * *}$ & $0.132^{* * *}$ & $0.075^{* * *}$ & $0.076^{* * *}$ \\
& $(0.072)$ & $(0.034)$ & $(0.023)$ & $(0.018)$ & $(0.016)$ \\
\hline Observations & 2399 & 2399 & 2399 & 2399 & 2399 \\
Baseline predicted probability & 0.123 & 0.043 & 0.029 & 0.024 & 0.022 \\
Pseudo - $R^{2}$ & 0.063 & & & & \\
\hline
\end{tabular}

Note: Columns (1) to (5) correspond to bottom extreme counts 1 to 5. In other words, column (1) presents the marginal effects in the case of one bottom count for the Euro-periphery group, and columns $(2),(3),(4),(5)$ correspond to two, three, four and five bottom counts for this group. The value of 0.147 for the Euro-periphery LT spread changes (column 2) means that an increase of 1 percent in the average Euro-periphery long term spread (vis-à-vis Germany) increases the probability of two Euro-periphery countries having extreme bottom stock returns by $14.7 \%$, while the value of 0.043 for the average exchange rate change (column 1) means that a one percent increase in the average Euro-periphery exchange rate increases the probability of one bottom Euro-periphery extreme return by $4.3 \%$.

$(* * *)$ : significance at $1 \%$ level

$(* *)$ : significance at $5 \%$ level

$(*)$ : significance at $10 \%$ level

Standard errors in parentheses. 
Table 4: Within groups summary results for bottom and top extreme return counts.

\begin{tabular}{|c|c|c|c|c|c|c|}
\hline \multirow[b]{2}{*}{ Entire Period } & \multicolumn{3}{|c|}{ Bottom tail } & \multicolumn{3}{|c|}{ Top tail } \\
\hline & & & & & & \\
\hline $\begin{array}{l}\text { Volatility } \\
\text { Exchange Rate Ch. } \\
\text { ST Interest Rate } \\
\text { LT Spread Change } \\
\text { Pseudo }-R^{2}\end{array}$ & $\begin{array}{l}\text { Non-euro } \\
++++ \\
+++++ \\
+++++ \\
0.081\end{array}$ & $\begin{array}{l}\text { Euro-periphery } \\
+++ \\
+++++ \\
-+ \\
++++ \\
0.063\end{array}$ & $\begin{array}{l}\text { Euro-core } \\
+++ \\
+++ \\
+ \\
+++ \\
0.052\end{array}$ & $\begin{array}{l}\text { Non-euro } \\
++++ \\
----- \\
-- \\
----- \\
0.086\end{array}$ & $\begin{array}{l}\text { Euro-periphery } \\
++++ \\
----- \\
- \\
----- \\
0.049\end{array}$ & $\begin{array}{l}\text { Euro-core } \\
++++ \\
---- \\
-- \\
--- \\
0.052\end{array}$ \\
\hline \multicolumn{7}{|l|}{ Pre-crisis Period } \\
\hline $\begin{array}{l}\text { Volatility } \\
\text { Exchange Rate Ch. } \\
\text { ST Interest Rate } \\
\text { LT Spread Change } \\
\text { Pseudo }-R^{2} \\
\end{array}$ & $\begin{array}{l}\text { Non-euro } \\
+++ \\
-- \\
+ \\
0.040 \\
\end{array}$ & $\begin{array}{l}\text { Euro-periphery } \\
+++ \\
- \\
+ \\
0.039 \\
\end{array}$ & $\begin{array}{l}\text { Euro-core } \\
++ \\
-\end{array}$ & $\begin{array}{l}\text { Non-euro } \\
+++ \\
- \\
- \\
0.044 \\
\end{array}$ & $\begin{array}{l}\text { Euro-periphery } \\
+ \\
+ \\
+ \\
0.016 \\
\end{array}$ & $\begin{array}{l}\text { Euro-core } \\
++ \\
+\end{array}$ \\
\hline \multicolumn{7}{|l|}{ US-crisis Period } \\
\hline $\begin{array}{l}\text { Volatility } \\
\text { Exchange Rate Ch. } \\
\text { ST Interest Rate } \\
\text { LT Spread Change } \\
\text { Pseudo }-R^{2}\end{array}$ & $\begin{array}{l}\text { Non-euro } \\
+++ \\
+++++ \\
+ \\
0.122 \\
\end{array}$ & $\begin{array}{l}\text { Euro-periphery } \\
++++ \\
++ \\
++ \\
++085\end{array}$ & $\begin{array}{l}\text { Euro-core } \\
++++ \\
+\end{array}$ & $\begin{array}{l}\text { Non-euro } \\
++++ \\
---- \\
-- \\
- \\
0.137\end{array}$ & $\begin{array}{l}\text { Euro-periphery } \\
++++ \\
- \\
- \\
-- \\
0.084\end{array}$ & $\begin{array}{l}\text { Euro-core } \\
+++++ \\
-- \\
--\end{array}$ \\
\hline \multicolumn{7}{|c|}{ Euro-crisis Period } \\
\hline $\begin{array}{l}\text { Volatility } \\
\text { Exchange Rate Ch. } \\
\text { ST Interest Rate } \\
\text { LT Spread Change } \\
\text { Pseudo }-R^{2}\end{array}$ & $\begin{array}{l}\text { Non-euro } \\
+ \\
++++ \\
+ \\
+ \\
0.194\end{array}$ & $\begin{array}{l}\text { Euro-periphery } \\
++ \\
++++ \\
+++ \\
0.176\end{array}$ & $\begin{array}{l}\text { Euro-core } \\
++ \\
+++\end{array}$ & $\begin{array}{l}\text { Non-euro } \\
++++ \\
---- \\
---- \\
0.172\end{array}$ & $\begin{array}{l}\text { Euro-periphery } \\
- \\
---- \\
- \\
0.119\end{array}$ & $\begin{array}{l}\text { Euro-core } \\
++++ \\
-- \\
---- \\
0.167\end{array}$ \\
\hline
\end{tabular}

Note: The number of "+" (or "-") indicate the number of statistically significant (in the $1 \%$ or $5 \%$ levels) and positive (or negative) marginal effects. For example, for the bottom tail returns and the entire period sample, all five volatility marginal effects are significant and positive for the Non-euro group (this is why we have five plus symbols at the Non-euro column), indicating that an increase in volatility increases the probability of extreme bottom returns in all five bottom extreme outcomes. For the top tail returns, the number of statistically significant marginal effects are five for the average exchange rate change in the Non-euro group, meaning that an increase in the average group's exchange rates (i.e. weaker group currencies on average) leads to lower probabilities of top Non-euro counts (for all five possible outcomes). 
Table 5: Across groups effects: Euro-periphery to Euro-core bottom extreme returns for the entire period. All reported coefficients are marginal effects.

\begin{tabular}{lccccc}
\hline \hline & $(1)$ & $(2)$ & $(3)$ & $(4)$ & $(5)$ \\
& & & & \\
& Margin / SE & Margin / SE & Margin / SE & Margin / SE & Margin / SE \\
\hline Constant & $-0.228^{* * *}$ & $-0.121^{* * *}$ & $-0.072^{* * *}$ & $-0.040^{* * *}$ & $-0.014^{* * *}$ \\
& $(0.017)$ & $(0.013)$ & $(0.011)$ & $(0.009)$ & $(0.005)$ \\
Volatility & 0.007 & 0.007 & $0.007^{* *}$ & 0.003 & $0.002^{* *}$ \\
& $(0.012)$ & $(0.007)$ & $(0.003)$ & $(0.002)$ & $(0.001)$ \\
Exchange Rate Change & -0.006 & -0.002 & 0.002 & -0.001 & 0.000 \\
& $(0.010)$ & $(0.006)$ & $(0.003)$ & $(0.002)$ & $(0.000)$ \\
ST Interest Rate & $0.009^{* *}$ & 0.002 & 0.001 & -0.000 & -0.000 \\
& $(0.004)$ & $(0.003)$ & $(0.001)$ & $(0.001)$ & $(0.000)$ \\
LT Spread Change & $0.847^{* * *}$ & 0.115 & 0.044 & 0.056 & 0.013 \\
& $(0.285)$ & $(0.157)$ & $(0.077)$ & $(0.044)$ & $(0.011)$ \\
Bottom Count Euro-periphery & $0.078^{* * *}$ & $0.041^{* * *}$ & $0.024^{* * *}$ & $0.014^{* * *}$ & $0.005^{* * *}$ \\
& $(0.009)$ & $(0.005)$ & $(0.004)$ & $(0.003)$ & $(0.002)$ \\
\hline Observations & 2399 & 2399 & 2399 & 2399 & 2399 \\
Baseline predicted probability & 0.069 & 0.030 & 0.023 & 0.020 & 0.045 \\
Pseudo $-R^{2}$ & 0.318 & & & & \\
\hline
\end{tabular}

Note: Columns (1) to (5) correspond to bottom counts 1 to 5. In other words, column (1) presents the marginal effects in the case of one bottom count for the group, and columns (2),(3),(4),(5) correspond to two, three, four and five bottom counts for this group. The value of 0.078 for the Euro-periphery bottom count (column 1) means that an increase of 1 Euro-periphery countries having extreme bottom returns increases the probability of one Euro-core country having extreme bottom stock returns (i.e. one bottom Euro-core count) by $7.8 \%$. The gray line corresponds to the gray line in Table 6 . $(* * *)$ : significance at $1 \%$ level $(* *)$ : significance at $5 \%$ level

$\left(^{*}\right)$ : significance at $10 \%$ level

Standard errors in parentheses. 
Table 6: Across groups effects: Euro-periphery to all groups for all periods. All reported coefficients are marginal effects.

$(1)$

$(2)$

$(3)$

$(4)$

$(5)$

Margin / SE Margin / SE $\quad$ Margin / SE $\quad$ Margin / SE $\quad$ Margin / SE $\quad$ Pseudo $-R^{2}$

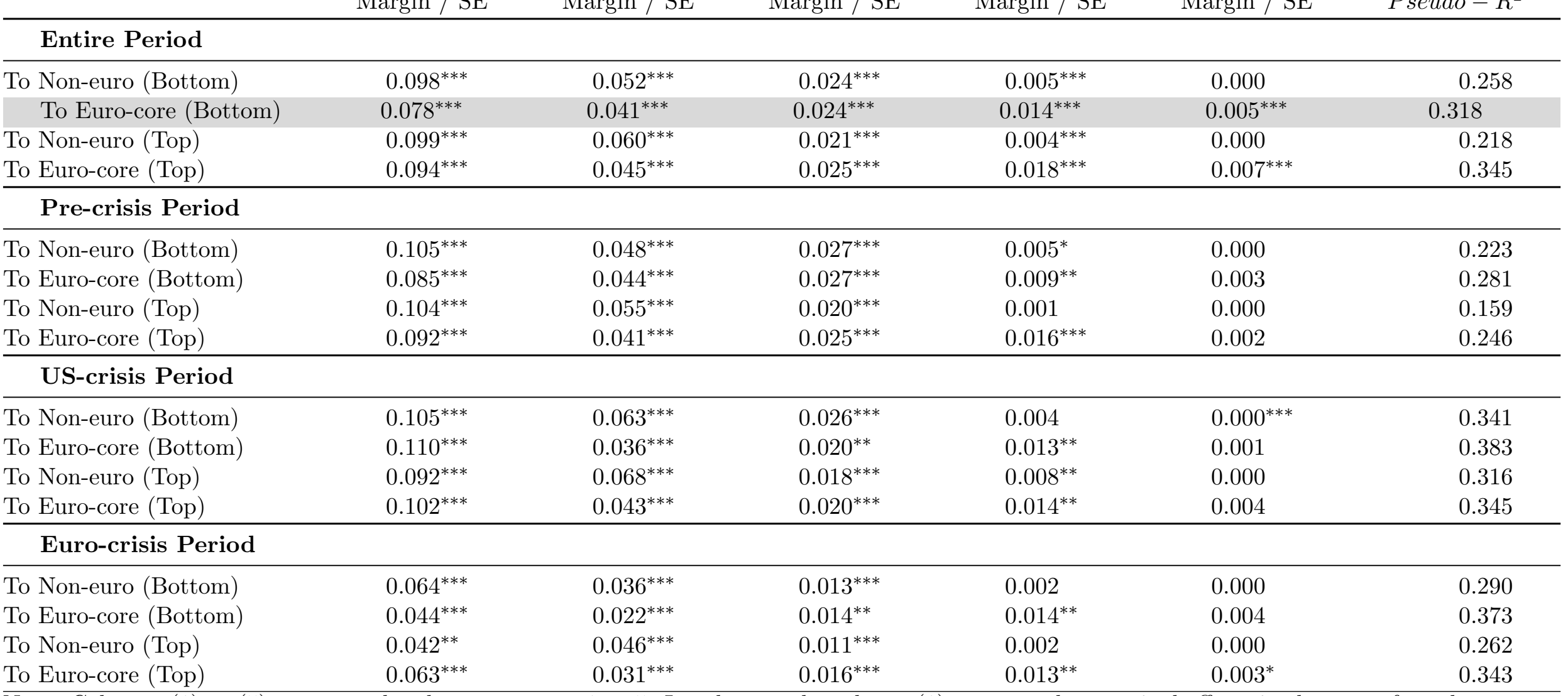

Note: Columns (1) to (5) correspond to bottom counts 1 to 5 . In other words, column (1) presents the marginal effects in the case of one bottom count for the Euro-periphery group, and columns $(2),(3),(4),(5)$ correspond to two, three, four and five bottom counts for this group. The value of 0.78 for the Euro-periphery bottom count (column 1) means that an increase of 1 in the number of Euro-periphery countries having extreme bottom returns increases the probability of one Euro-core country having extreme bottom stock returns (i.e. one bottom Euro-core count) by $7.8 \%$ for the Entire period, $8.5 \%$ in the Pre-crisis period, $11.0 \%$ in the US-crisis period and $4.4 \%$ in the Euro-crisis period. The gray line corresponds to the gray line in Table 5 .

$(* * *)$ : significance at $1 \%$ level

$(* *)$ : significance at $5 \%$ level

$(*)$ : significance at $10 \%$ level 
Table 7: Across groups summary results for bottom and top extreme counts.

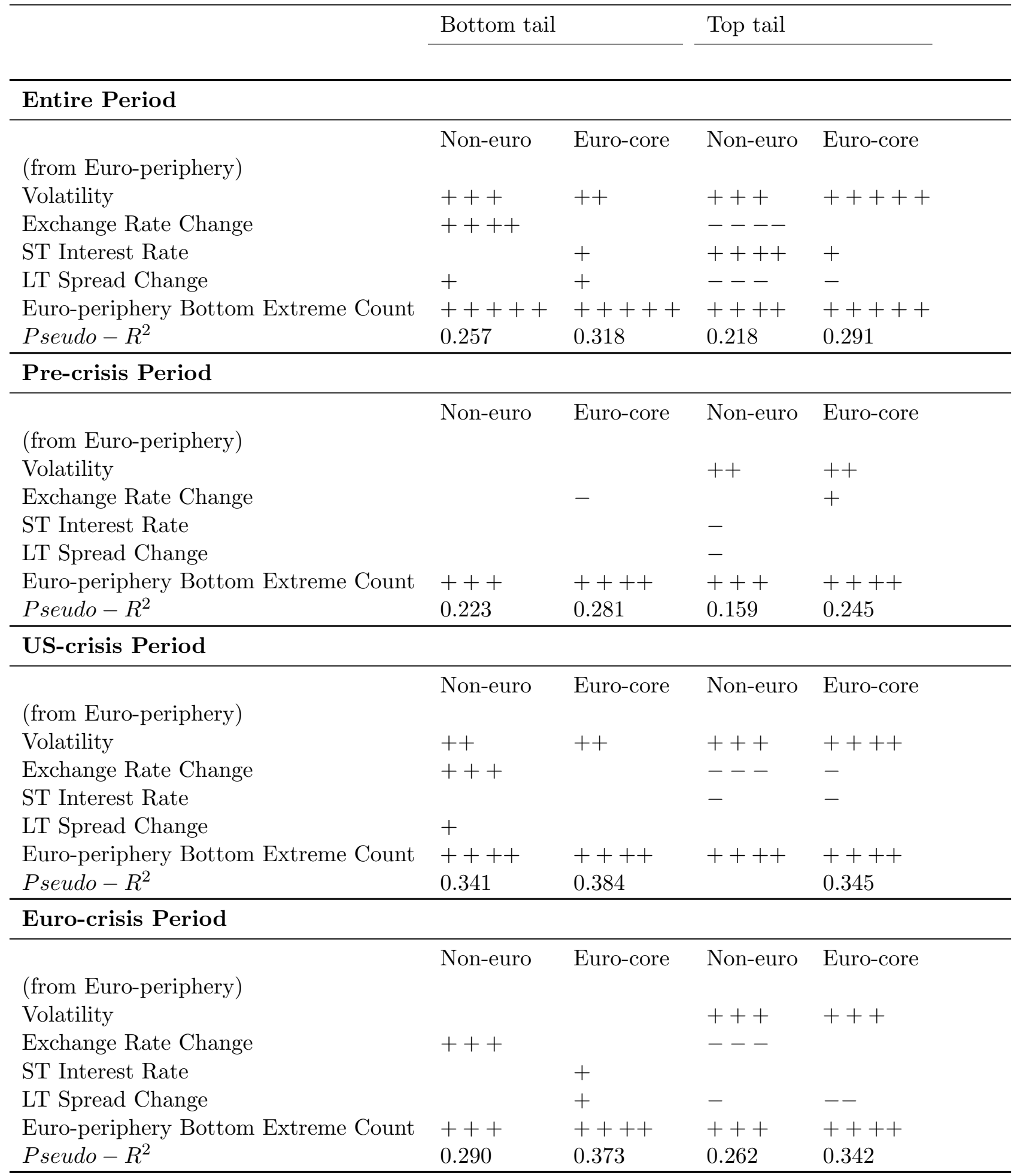

Note: The number of "+" (or "-") indicate the number of statistically significant (in the 1\% or $5 \%$ levels) and positive (or negative) marginal effects. For example, for the bottom tail returns and the entire period sample, three out of five volatility marginal effects are significant and positive for the Non-euro group, indicating that an increase in volatility increases the probability of bottom Non-euro extreme counts in three out of five outcomes. For the top tail returns, the number of statistically significant marginal effects are four for the average exchange rate change, and have a negative sign in all four cases, meaning that an increase in the average group's exchange rates (i.e. weaker group currencies on average) lead to lower probabilities of extreme top returns in four out of five top Non-euro outcomes. 
Table 8: Likelihood ratio tests.

\begin{tabular}{|c|c|c|c|c|}
\hline \multicolumn{5}{|c|}{ Euro-periphery to Euro-core } \\
\hline \multicolumn{2}{|l|}{ Model } & \multirow{2}{*}{$\frac{\text { Obs }}{2399}$} & \multirow{2}{*}{$\begin{array}{l}\mathrm{df} \\
30\end{array}$} & \multirow{2}{*}{$\begin{array}{c}\text { Prob }>\text { chi } 2 \\
0.000\end{array}$} \\
\hline Nested & Entire period & & & \\
\hline \multirow{3}{*}{ Non-nested } & Pre-crisis & 822 & 30 & \\
\hline & US-crisis & 725 & 30 & \\
\hline & Euro-crisis & 852 & 30 & \\
\hline Nested & Pre-crisis, US-crisis & 1547 & 30 & 0.0077 \\
\hline \multirow[t]{2}{*}{ Non-nested } & Pre-crisis & 822 & 30 & \\
\hline & US-crisis & 725 & 30 & \\
\hline Nested & US-crisis, Euro-crisis & 1577 & 30 & 0.0000 \\
\hline \multirow[t]{2}{*}{ Non-nested } & US-crisis & 725 & 30 & \\
\hline & Euro-crisis & 852 & 30 & \\
\hline 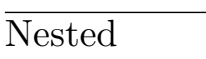 & Pre-crisis, Euro-crisis & 1674 & 30 & 0.0304 \\
\hline \multirow{2}{*}{ Non-nested } & Pre-crisis & 822 & 30 & \\
\hline & Euro-crisis & 852 & 30 & \\
\hline \multicolumn{5}{|c|}{ Euro-periphery to Non-euro } \\
\hline \multicolumn{2}{|c|}{ Model } & Obs & $\mathrm{df}$ & Prob $>$ chi2 \\
\hline \multirow{4}{*}{$\begin{array}{l}\text { Nested } \\
\text { Non-nested }\end{array}$} & Entire period & 2399 & 30 & 0.000 \\
\hline & Pre-crisis & 822 & 30 & \\
\hline & US-crisis & 725 & 30 & \\
\hline & Euro-crisis & 852 & 30 & \\
\hline \multirow{3}{*}{$\begin{array}{l}\text { Nested } \\
\text { Non-nested }\end{array}$} & Pre-crisis, US-crisis & 1547 & 30 & 0.000 \\
\hline & Pre-crisis & 822 & 30 & \\
\hline & US-crisis & 725 & 30 & \\
\hline \multirow{3}{*}{$\begin{array}{l}\text { Nested } \\
\text { Non-nested }\end{array}$} & US-crisis, Euro-crisis & 1577 & 30 & 0.0128 \\
\hline & US-crisis & 725 & 30 & \\
\hline & Euro-crisis & 852 & 30 & \\
\hline \multirow{3}{*}{$\begin{array}{l}\text { Nested } \\
\text { Non-nested }\end{array}$} & Pre-crisis, Euro-crisis & 1674 & 30 & 0.0010 \\
\hline & Pre-crisis & 822 & 30 & \\
\hline & Euro-crisis & 852 & 30 & \\
\hline
\end{tabular}

Note: Likelihood ratio tests for the Entire Period, the Pre-crisis Period, the US-crisis Period and the Euro-crisis Period models. Obs denotes the number of observations for each model, df is the number of degrees of freedom. 
Table 9: $10 \%$ percentiles for the extreme bottom returns (\%) of the three country-groups for all subperiods.

\begin{tabular}{llll}
\hline & Non-euro & Euro-periphery & Euro-core \\
\hline Pre-crisis & -0.957 & -0.742 & -0.831 \\
US-crisis & -2.037 & -2.060 & -2.011 \\
Euro-crisis & -1.262 & -1.903 & -1.450 \\
\hline
\end{tabular}


Table 10: Average returns (\%) on days with extreme bottom outcomes, for all subperiods.

\begin{tabular}{lcrrrr}
\hline & $(1)$ & $(2)$ & $(3)$ & $(4)$ & $(5)$ \\
\hline Pre-crisis & & & & \\
\hline Non-euro & -1.341 & -1.514 & -1.501 & -1.694 & -2.624 \\
Euro-periphery & -1.076 & -1.108 & -1.128 & -1.512 & -1.843 \\
Euro-core & -1.154 & -1.179 & -1.141 & -1.214 & -1.776 \\
\hline US-crisis & & & & \\
\hline Non-euro & -2.570 & -2.829 & -3.222 & -3.346 & -5.156 \\
Euro-periphery & -2.691 & -2.978 & -2.912 & -3.484 & -4.238 \\
Euro-core & -2.732 & -2.709 & -2.734 & -2.819 & -4.236 \\
\hline Euro-crisis & & & & & \\
\hline Non-euro & -1.606 & -1.793 & -1.894 & -2.565 & -2.852 \\
Euro-periphery & -2.759 & -2.574 & -2.718 & -2.888 & -3.749 \\
Euro-core & -1.848 & -1.689 & -1.759 & -2.162 & -2.802 \\
\hline Note: Coln & & & & & \\
\hline
\end{tabular}

Note: Columns one (1) to five (5) correspond to the count of extreme bottom returns. For example, column one (1) corresponds to one country in the group having an extreme bottom return on this day, while column five (5) corresponds to all five (5) countries in the group having extreme bottom returns on the same day. 
Table 11: T-tests for coefficients equality, for three periods. The table reports the p-values for the t-tests

\begin{tabular}{llllll} 
& $(1)$ & $(2)$ & $(3)$ & $(4)$ & $(5)$ \\
& & & & & \\
& p-value & p-value & p-value & p-value & p-value \\
\hline Periphery To Core & & & & & \\
\hline Pre-crisis/US-crisis & 0.0002 & 0.0001 & 0.0062 & 0.0404 & 0.0446 \\
Pre-crisis/Euro-crisis & 0.8766 & 0.5512 & 0.0181 & 0.9549 & 0.1080 \\
US-crisis/Euro-crisis & 0.0001 & 0.0000 & 0.1461 & 0.0384 & 0.2132 \\
\hline Periphery To Eu & & & & & \\
\hline Pre-crisis/US-crisis & 0.0370 & 0.0004 & 0.0114 & 0.0592 & 0.1726 \\
Pre-crisis/Euro-crisis & 0.3395 & 0.4863 & 0.0267 & 0.0783 & 0.3351 \\
US-crisis/Euro-crisis & 0.0013 & 0.0009 & 0.0000 & 0.0025 & 0.0540 \\
\hline
\end{tabular}


Table 12: VAR Specification.

(1)

To Euro-core

Coef.

\section{Pre-crisis}

Periphery Returns $s_{t-1} \quad-0.063$

Periphery Returns $s_{t-2} \quad-0.109$

Periphery Returns $s_{t-3} \quad-0.008$

Periphery Returns $s_{t-4} \quad 0.099$

Periphery Returns $s_{t-5} \quad 0.048$

\section{US-crisis}

\begin{tabular}{lllll}
\hline Periphery Return $s_{t-1}$ & $-0.295^{* * *}$ & 0.005 & 0.016 & 0.869 \\
Periphery Return $s_{t-2}$ & -0.022 & 0.835 & -0.071 & 0.461 \\
Periphery Return $s_{t-3}$ & $0.282^{* * *}$ & 0.007 & 0.091 & 0.346 \\
Periphery Return $s_{-4}$ & -0.040 & 0.705 & -0.138 & 0.152 \\
Periphery Return $s_{t-5}$ & $-0.427^{* * *}$ & $<0.001$ & -0.055 & 0.564 \\
\hline Euro-crisis & & & & \\
\hline Periphery Return $s_{t-1}$ & 0.106 & 0.134 & 0.030 & 0.548 \\
Periphery Return $s_{t-2}$ & -0.014 & 0.835 & 0.025 & 0.607 \\
Periphery Return $s_{t-3}$ & -0.023 & 0.742 & -0.058 & 0.541 \\
Periphery Return $s_{t-4}$ & -0.048 & 0.496 & -0.060 & 0.532 \\
Periphery Return $s_{t-5}$ & 0.040 & 0.566 & 0.029 & 0.548 \\
\hline
\end{tabular}

p-value

(2)

To Non-euro

p-value

0.817

0.600

$\begin{array}{lll}0.339 & 0.038 & 0.600 \\ 0.924 & -0.051 & 0.479\end{array}$

$\begin{array}{lll}0.270 & 0.007 & 0.915\end{array}$

$\begin{array}{lll}0.587 & -0.035 & 0.624\end{array}$

$(* * *)$ : significance at $1 \%$ level

$(* *)$ : significance at $5 \%$ level

$(*)$ : significance at $10 \%$ level 
Table 13: Dynamic Conditional Correlation (DCC) Specification.

(1)

To Euro-core

\begin{tabular}{|c|c|c|c|c|}
\hline & Coefficient & p-value & Coefficient & p-value \\
\hline Periphery Returns ${ }_{\text {Pre-crisis }, t-1}$ & 0.042 & 0.367 & 0.071 & 0.115 \\
\hline Periphery Returns $s_{U S-\text { crisis,t-1 }}$ & -0.035 & 0.375 & -0.018 & 0.635 \\
\hline Periphery Returns Euro-crisis,$t-1_{1}$ & $0.061^{*}$ & 0.084 & -0.012 & 0.651 \\
\hline LT SpreadChange $e_{t-1}$ & 1.482 & 0.205 & -0.361 & 0.612 \\
\hline Exchange Rate Change $_{t-1}$ & 0.024 & 0.438 & $-0.047^{*}$ & 0.085 \\
\hline ST Interest Rate $_{t-1}$ & -0.019 & 0.164 & -0.009 & 0.511 \\
\hline Volatility $_{t-1}$ & 0.060 & 0.258 & -0.003 & 0.954 \\
\hline$A R C H_{t-1}$ & $0.101^{* * *}$ & 0.000 & $0.108^{* * *}$ & 0.000 \\
\hline$G A R C H_{t-1}$ & $0.886^{* * *}$ & 0.000 & $0.878^{* * *}$ & 0.000 \\
\hline
\end{tabular}

$(* * *)$ : significance at $1 \%$ level

(2)

To Non-euro

$(* *)$ : significance at $5 \%$ level

$(*)$ : significance at $10 \%$ level 
Table 14: The effect of USA extreme stock returns.
(1)
(2)
(3)
(4)

$(5)$

Margin / SE Margin / SE Margin / SE Margin / SE Margin / SE

\begin{tabular}{|c|c|c|c|c|c|}
\hline \multicolumn{6}{|l|}{ To Euro-core } \\
\hline \multicolumn{6}{|l|}{ Periphery to Core } \\
\hline \multirow[t]{2}{*}{$Y_{\text {Periphery }, t, P r e-c r i s i s}$} & 0.051 & 0.007 & 0.000 & 0.007 & 0.000 \\
\hline & $(0.044)$ & $(0.618)$ & $(0.050)$ & $(0.005)$ & $(0.000)$ \\
\hline \multirow[t]{2}{*}{$Y_{\text {Periphery }, t, U S-\text { crisis }}$} & $0.158^{* * *}$ & $0.088^{* * *}$ & $0.021^{* *}$ & $0.024^{* *}$ & $0.005^{*}$ \\
\hline & $(0.029)$ & $(0.017)$ & $(0.009)$ & $(0.010)$ & $(0.003)$ \\
\hline \multirow{2}{*}{$Y_{\text {Periphery,t,Euro-crisis }}$} & $0.050^{* * *}$ & $0.009^{* *}$ & $0.012^{* * *}$ & $0.008^{* *}$ & 0.001 \\
\hline & $(0.011)$ & $(0.003)$ & $(0.004)$ & $(0.004)$ & $(0.001)$ \\
\hline \multicolumn{6}{|l|}{ USA to Core } \\
\hline \multirow[t]{2}{*}{$Y_{U S A, t, P r e-c r i s i s}$} & 0.060 & -0.045 & -0.002 & 0.003 & 0.000 \\
\hline & $(0.095)$ & $(1.681)$ & $(0.174)$ & $(0.007)$ & $(0.000)$ \\
\hline \multirow[t]{2}{*}{$Y_{U S A, t, U S-\text { crisis }}$} & $0.182^{* * *}$ & 0.046 & $0.019^{* *}$ & $0.026^{* *}$ & $0.006^{*}$ \\
\hline & $(0.054)$ & $(0.029)$ & $(0.009)$ & $(0.011)$ & $(0.003)$ \\
\hline \multirow[t]{2}{*}{$Y_{U S A, t, \text { Euro-crisis }}$} & $0.102^{* * *}$ & $0.020^{* *}$ & $0.017^{* *}$ & $0.013^{*}$ & 0.002 \\
\hline & $(0.039)$ & $(0.009)$ & $(0.008)$ & $(0.007)$ & $(0.002)$ \\
\hline \multicolumn{6}{|c|}{ Lagged USA to Core } \\
\hline \multirow[t]{2}{*}{$Y_{U S A, t-1, \text { Pre-crisis }}$} & 0.044 & 0.002 & -0.002 & 0.006 & $0.000^{* * *}$ \\
\hline & $(0.034)$ & $(0.137)$ & $(0.180)$ & $(0.004)$ & $(0.000)$ \\
\hline \multirow[t]{2}{*}{$Y_{U S A, t-1, U S-\text { crisis }}$} & $0.096^{*}$ & 0.024 & $0.014^{*}$ & 0.006 & 0.001 \\
\hline & $(0.055)$ & $(0.029)$ & $(0.008)$ & $(0.007)$ & $(0.001)$ \\
\hline \multirow{2}{*}{$Y_{U S A, t-1, \text { Euro-crisis }}$} & $0.082^{* *}$ & $0.015^{*}$ & $0.012^{*}$ & 0.008 & 0.001 \\
\hline & $(0.035)$ & $(0.008)$ & $(0.007)$ & $(0.005)$ & $(0.001)$ \\
\hline \multicolumn{6}{|c|}{ To Non-euro } \\
\hline \multicolumn{6}{|c|}{ Periphery to Non-euro } \\
\hline \multirow{2}{*}{$Y_{\text {Periphery,t,Pre-crisis }}$} & $0.054^{* * *}$ & $0.019^{* * *}$ & $0.024^{* * *}$ & 0.005 & 0.000 \\
\hline & $(0.013)$ & $(0.006)$ & $(0.007)$ & $(0.004)$ & $(0.000)$ \\
\hline \multirow[t]{2}{*}{$Y_{\text {Periphery }, t, U S-\text { crisis }}$} & $0.080^{* * *}$ & $0.060^{* * *}$ & $0.060^{* * *}$ & $0.022^{* * *}$ & $0.005^{*}$ \\
\hline & $(0.016)$ & $(0.011)$ & $(0.011)$ & $(0.007)$ & $(0.003)$ \\
\hline \multirow[t]{2}{*}{$Y_{\text {Periphery,t,Euro-crisis }}$} & $0.030^{* * *}$ & $0.020^{* * *}$ & $0.005^{* *}$ & 0.001 & 0.000 \\
\hline & $(0.007)$ & $(0.005)$ & $(0.002)$ & $(0.001)$ & $(0.000)$ \\
\hline \multicolumn{6}{|l|}{ USA to Non-euro } \\
\hline \multirow[t]{2}{*}{$Y_{U S A, t, \text { Pre-crisis }}$} & -0.019 & 0.006 & 0.016 & -0.001 & -0.000 \\
\hline & $(0.040)$ & $(0.009)$ & $(0.014)$ & $(0.005)$ & $(0.000)$ \\
\hline \multirow[t]{2}{*}{$Y_{U S A, t, U S-\text { crisis }}$} & $0.133^{* * *}$ & $0.072^{* * *}$ & -0.029 & $0.017^{*}$ & 0.005 \\
\hline & $(0.037)$ & $(0.021)$ & $(0.032)$ & $(0.009)$ & $(0.003)$ \\
\hline \multirow[t]{2}{*}{$Y_{U S A, t, \text { Euro-crisis }}$} & $0.090^{* * *}$ & $0.045^{* * *}$ & $0.014^{*}$ & 0.001 & 0.000 \\
\hline & $(0.023)$ & $(0.014)$ & $(0.007)$ & $(0.001)$ & $(0.000)$ \\
\hline \multicolumn{6}{|c|}{ Lagged USA to Non-euro } \\
\hline \multirow[t]{2}{*}{$Y_{U S A, t-1, \text { Pre-crisis }}$} & -0.006 & 0.009 & 0.011 & 0.004 & 0.000 \\
\hline & $(0.036)$ & $(0.009)$ & $(0.016)$ & $(0.004)$ & $(0.000)$ \\
\hline$Y_{U S A, t-1, U S-\text { crisis }}$ & 0.061 & 0.013 & -0.011 & 0.004 & 0.003 \\
\hline & $(0.039)$ & $(0.022)$ & $(0.029)$ & $(0.008)$ & $(0.002)$ \\
\hline$Y_{U S A, t-1, \text { Euro-crisis }}$ & $0.048^{* *}$ & $0.022^{*}$ & $0.009^{*}$ & 0.001 & 0.000 \\
\hline & $(0.022)$ & $(0.011)$ & $(0.005)$ & $(0.001)$ & $(0.000)$ \\
\hline
\end{tabular}

Note: Columns (1) to (5) correspond to bottom counts 1 to 5 for each group. The value of 0.182 for the Euro-core bottom count (column 1) during the US-crisis, means that an extreme bottom return in the US increases the probability of one Euro-core country having extreme bottom stock returns (i.e. one bottom Euro-core count) by $18.2 \%$ for the US-crisis period.

$(* * *)$ : significance at $1 \%$ level

$(* *)$ : significance at $5 \%$ level

$(*)$ : significance at $10 \%$ level

Standard errors in parentheses. 
Fig. 1. Extreme bottom return counts for all three country groups, for the entire period.
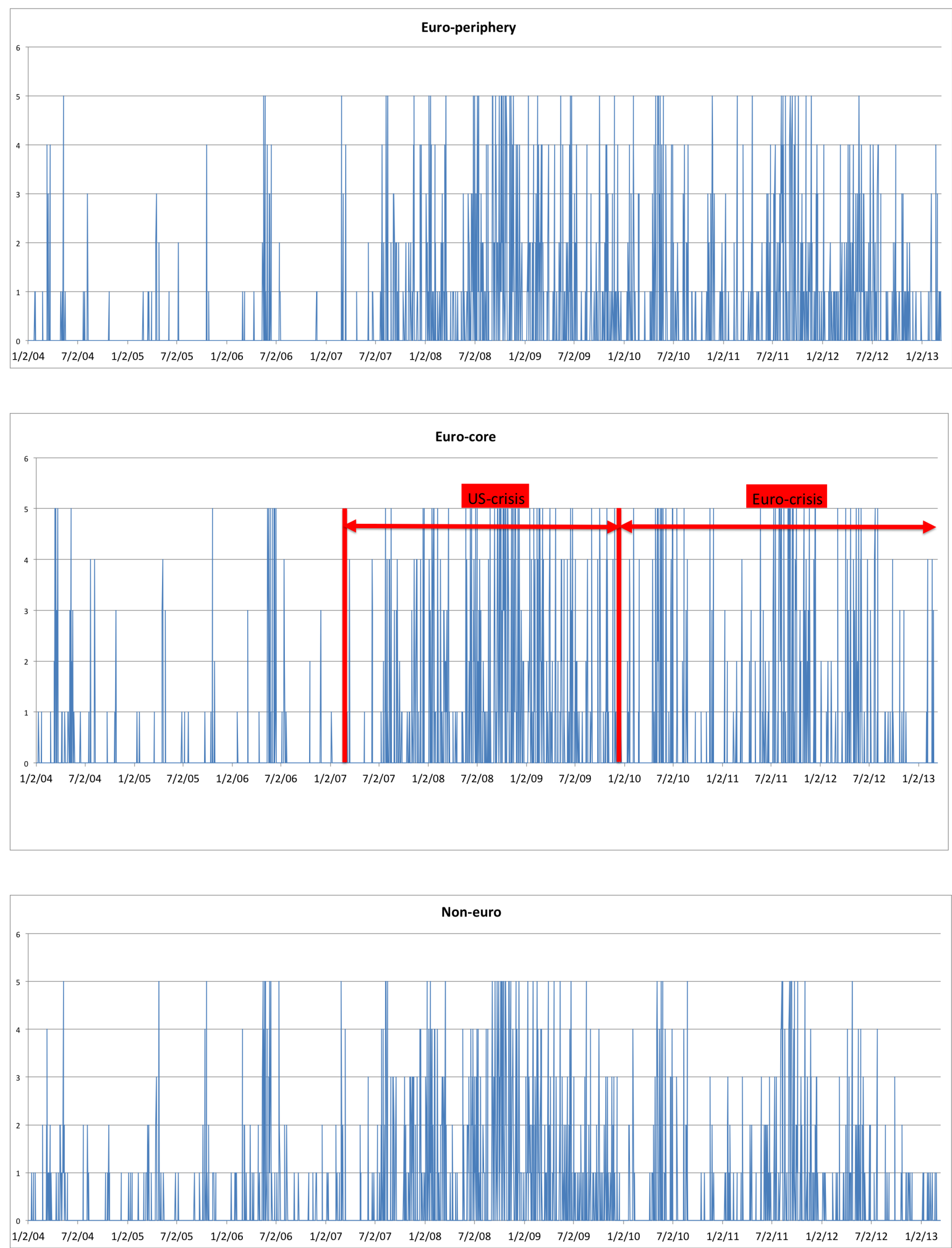
Fig. 2. Coexceedances response curves for one to five bottom extreme returns for the Euro-core and the Non-euro groups.
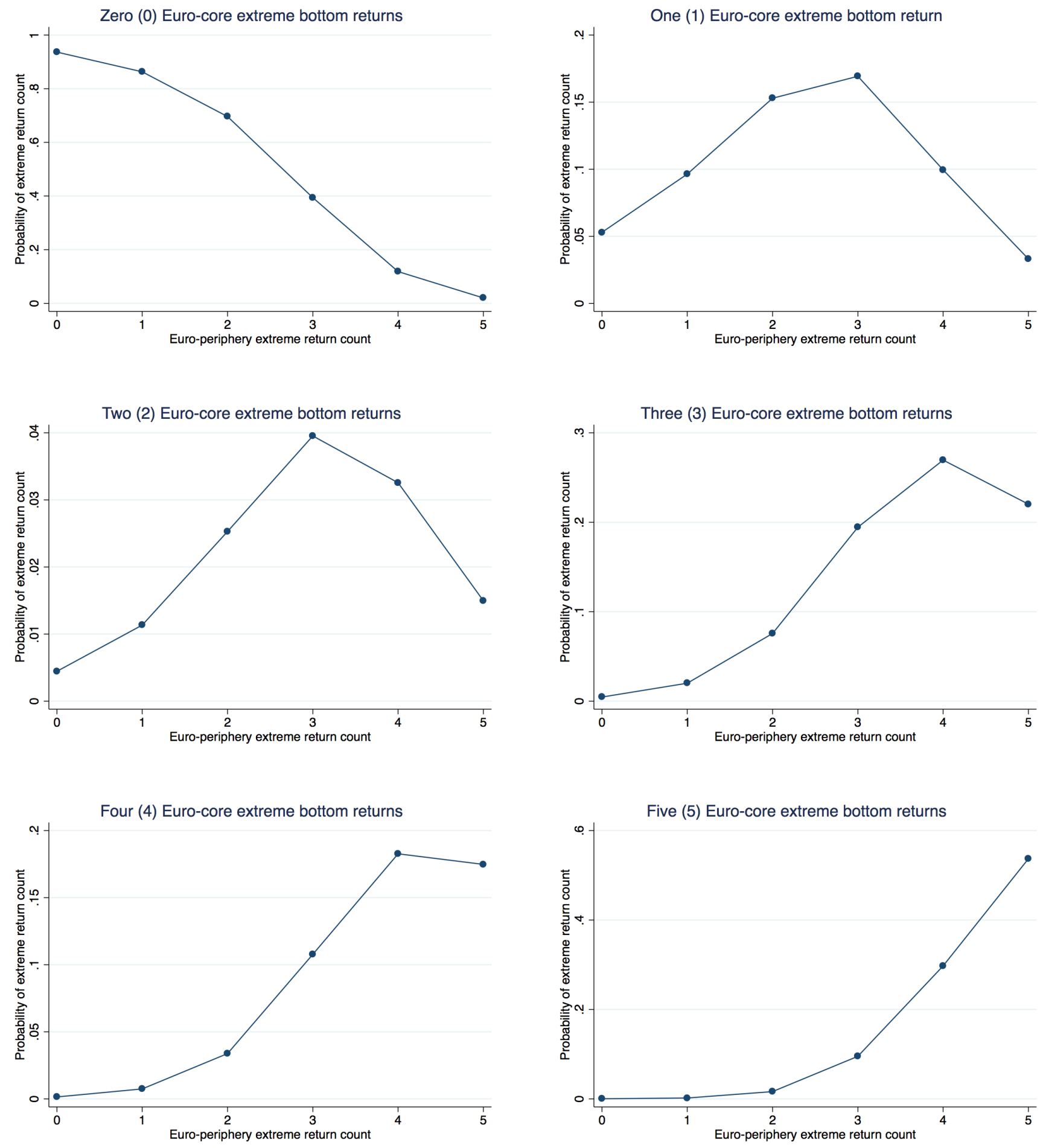